\title{
Operational C-Band Dual-Polarization Radar QPE for the Subtropical Complex Terrain of Taiwan
}

\author{
Yadong Wang, ${ }^{1,2}$ Jian Zhang, ${ }^{2}$ Pao-Liang Chang, ${ }^{3}$ Carrie Langston, ${ }^{1,2}$ \\ Brian Kaney, ${ }^{1,2}$ and Lin Tang ${ }^{1,2}$ \\ ${ }^{1}$ Cooperative Institute for Mesoscale Meteorological Studies, University of Oklahoma, Norman, OK, USA \\ ${ }^{2}$ NOAA/OAR National Severe Storms Laboratory, Norman, OK 73072, USA \\ ${ }^{3}$ Central Weather Bureau, Taipei, Taiwan \\ Correspondence should be addressed to Yadong Wang; yadong.wang@noaa.gov
}

Received 15 July 2015; Revised 27 September 2015; Accepted 28 September 2015

Academic Editor: Hiroyuki Hashiguchi

Copyright @ 2016 Yadong Wang et al. This is an open access article distributed under the Creative Commons Attribution License, which permits unrestricted use, distribution, and reproduction in any medium, provided the original work is properly cited.

\begin{abstract}
Complex terrain poses significant challenges to the radar based quantitative precipitation estimation (QPE) because of blockages to the lower tilts of radar observations. The blockages often force the use of higher tilts data to estimate precipitation at the ground and result in errors due to vertical variations of the radar variables. To obtain accurate radar QPEs in the subtropical complex terrain of Taiwan, a vertically corrected composite algorithm (VCCA) was developed for two C-band polarimetric radars. The new algorithm corrects higher tilt radar variables with the vertical profile of reflectivity (VPR) or vertical profile of specific differential phase (VPSDP) and estimates rainfall rate at the ground through an automated combination of $R-Z$ and $R-K_{\mathrm{DP}}$ relations. The VCCA was assessed with three precipitation cases of different regimes including typhoon, mei-yu, and summer stratiform precipitation events. The results showed that a combination of $R-Z$ and $R-K_{\mathrm{Dp}}$ relations provided more accurate QPEs than each alone because $R-Z$ provides better rainfall estimates for light rains and $R-K_{\mathrm{DP}}$ relation is more suitable for heavy rains. The vertical profile corrections for reflectivity and specific differential phase significantly reduced radar QPE errors caused by inadequate sampling of the orographic enhancement of precipitation near the ground.
\end{abstract}

\section{Introduction}

Polarimetric radars have shown great potential in hydrometeorological researches and for operational applications in weather agencies. The researches of polarimetric radars were applied in fields of cloud physics study, radar data quality control, quantitative precipitation estimation (QPE), tornado signatures investigation, and so forth (e.g., [1-5]). One of the primary benefits of polarimetric radar is its capability of measuring the differential reflectivity $Z_{\mathrm{DR}}$, specific differential phase $K_{\mathrm{DP}}$, and the cross correlation coefficient $\rho_{\mathrm{HV}}$ between two orthogonally polarized radar returns. With the dual-polarization measurements, a variety of polarimetric QPE algorithms have been developed in the last decade. The relations utilizing different combinations of $Z, Z_{\mathrm{DR}}$, and $K_{\mathrm{DP}}$ were obtained using either simulated or measured drop size distribution (DSD) and drop shape relations (DSR) (e.g.,
$[4,6-8])$. Comparing to conventional $R-Z$ approaches, the polarimetric rainfall estimation algorithms were shown to deliver enhanced rainfall estimation because of polarimetric variables' ability of improving the radar data quality, distinguishing rain echoes from other echoes (snow, hail, and clutter), and reducing the impact of DSD variability [9].

Ryzhkov et al. [9] developed a synthetic rainfall estimation algorithm on a Weather Surveillance Radar-1988 Doppler (WSR-88D) KOUN operated by National Severe Storms Laboratory (NSSL). This synthetic algorithm automatically selects the optimal estimator from the combination of $R\left(Z, Z_{\mathrm{DR}}\right), R\left(K_{\mathrm{DP}}, Z_{\mathrm{DR}}\right)$, and $R\left(K_{\mathrm{DP}}\right)$ according to various thresholds of rain intensities [9]. The algorithm was tested with 24 rain events and resulted in significant reductions in the root mean square errors when compared with the conventional $R(Z)$ relation [9]. Recently, Bringi et al. [4] developed a similar composite approach particularly for 
a C-band polarimetric radar located in the United Kingdom. According to a comparison with a gauge network, Bringi's approach was shown to provide more accurate rainfall estimation than other estimators that only employ single radar variable (such as $R(Z)$ or $R\left(K_{\mathrm{DP}}\right)$ ). Although the synthetic [9]/composite [4] algorithm was proven to produce optimal rainfall rate estimation in different precipitation types, this type of methodology has not been applied in complex terrain especially when the radar beams from low elevation angle are severely blocked.

Complex terrain often poses significant challenges to the radar based QPE due to partial or total radar beam blockages. Variables measuring the magnitude of the return echoes, such as $Z$ and $Z_{\mathrm{DR}}$, are significantly affected by the beam blockage, and the estimated rainfall is biased if the beam blockage cannot be effectively corrected. In addition, severe beam blockages force the use of radar data from the higher tilts/altitudes and result in errors caused by vertical variations of precipitation (e.g., orographic growth or evaporation). Projecting reflectivities from higher tilts to the ground level through vertical profile of reflectivity (VPR) correction is one of the methods that can mitigate QPE errors due to orographic effects (e.g., $[10,11,21])$. Although some studies (e.g., $[12,13])$ had indicated that the specific differential phase $K_{\mathrm{DP}}$ was immune to attenuation and miscalibration, severe beam blockages still cause missing or unreliable $K_{\mathrm{DP}}[8]$, and higher tilt $K_{\mathrm{DP}}$ data should be corrected for nonuniform vertical profile of specific differential phase (VPSDP) before being used in the rainfall estimation. Wang et al. [8] showed that the $R-K_{\mathrm{DP}}$ with VPSDP-based correction produced significantly improved rainfall estimation in mountain regions over the conventional $R-Z$ relation.

In this work, a vertically corrected composite algorithm (VCCA) was developed for two C-band polarimetric radars located in Taiwan. The new algorithm is unique in that it automatically combines locally derived $R-Z$ and $R-K_{\mathrm{DP}}$ relationships with VPR and VPSDP corrections. It is physically based and computationally efficient, thus suitable for operational implementation. Moreover, the VCCA methodology can be easily adapted for operational QPEs in other complex terrain regions.

This paper is organized as follows. Section 2 provides information on radar data sources and processing. The DSD/DSR measurements and the $R-Z, R-K_{\mathrm{DP}}$ derivations are described in Section 3 . The vertically corrected composite algorithm and its performance are presented in Sections 4 and 5, respectively. A summary and conclusions are provided in Section 6.

\section{Radar Data Sources and Processing}

2.1. C-Band Radar Network. The C-band radar network used in the current work consists of two C-band polarimetric radars of RCCK (located at Ching Chung Kong) and RCMK (located at Makung) as shown in Figure 1. The Weather Wing of the Chinese Air Force deployed these two radars and made the data available to the Central Weather Bureau (CWB) of Taiwan since 2009. Together with other 4 Sband single-polarization WSR-88D, these 6 radars provide

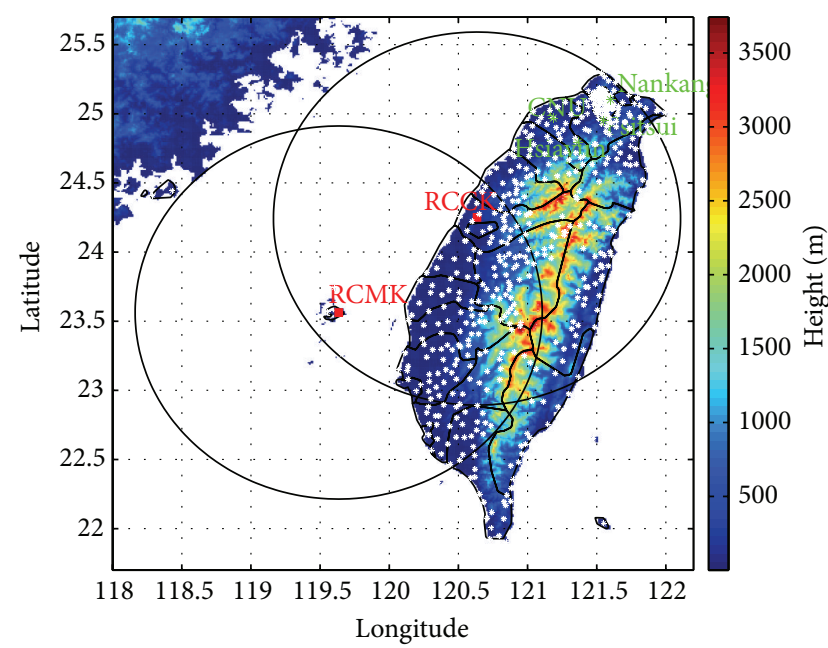

Figure 1: The locations of the C-band dual-polarization radars (marked with red squares), JWDs (marked with green stars), and the gauge network (marked with white stars) used in the current work. The black circles indicate the radar coverage ranges of $150 \mathrm{~km}$.

TABLE 1: Technical specifications of two C-band polarimetric radars (RCMK, RCCK) used in the current work.

\begin{tabular}{lcc}
\hline & RCMK & RCCK \\
\hline Polarization & $\begin{array}{c}\text { Linear } H / V: \\
\text { simultaneous } \\
\text { transmission }\end{array}$ & $\begin{array}{c}\text { Linear } H / V: \\
\text { simultaneous } \\
\text { transmission }\end{array}$ \\
Wavelength (cm) & 5.291 & 5.338 \\
$\begin{array}{l}\text { Beamwidth at half power } \\
\text { (degrees) }\end{array}$ & 0.94 & 0.95 \\
Peak power (kw) & 276 & 304 \\
Noise power (dB) & -44.61 & -43.87 \\
PRF (Hz) & $749 \sim 937$ & $749 \sim 937$ \\
Lat. (degrees) & 23.5629 & 24.2509 \\
Long. (degrees) & 119.6343 & 120.6343 \\
Height (AGL, m) & 48 & 203 \\
\hline
\end{tabular}

real-time QPEs for CWB to support missions of flood monitoring and prediction, landslide forecasts, and water resource management. These two $\mathrm{C}$-band polarimetric radars perform volume scans of 10 tilts $\left(0.5^{\circ}, 1.4^{\circ}, 2.4^{\circ}, 3.4^{\circ}, 4.3^{\circ}\right.$, $6.0^{\circ}, 9.9^{\circ}, 14.6^{\circ}, 19.5^{\circ}$, and $\left.25^{\circ}\right)$ every 5 minutes with the range resolution of $500 \mathrm{~m}$ and angular sampling of 1 degree. The key system characteristics are listed in Table 1 as a reference.

As shown in Figure 1, RCMK and RCCK cover most part of Taiwan and have an overlapping coverage area of approximately $1 / 3$ of Taiwan Island. However, radar beams from the lower tilts of these two radars suffer severe blockages from the terrain of the Central Mountain Range (CMR), which peaks at nearly $4000 \mathrm{~m}$ above the mean sea level (MSL). Significant amounts of data in the lower tilts $\left(0.5^{\circ}\right.$ for RCMK and up to $3.4^{\circ}$ for RCCK) become unavailable or unreliable because of the total/severe blockages. Figure 2 


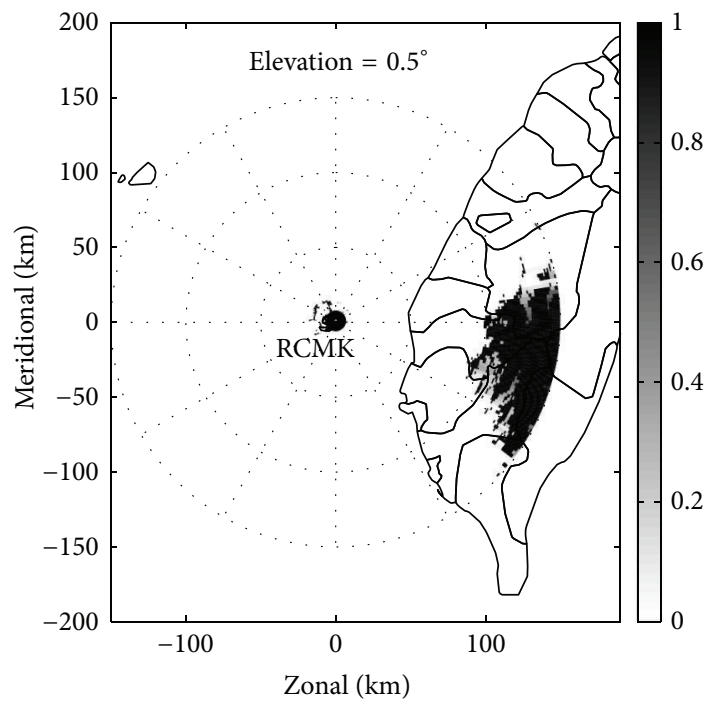

(a)

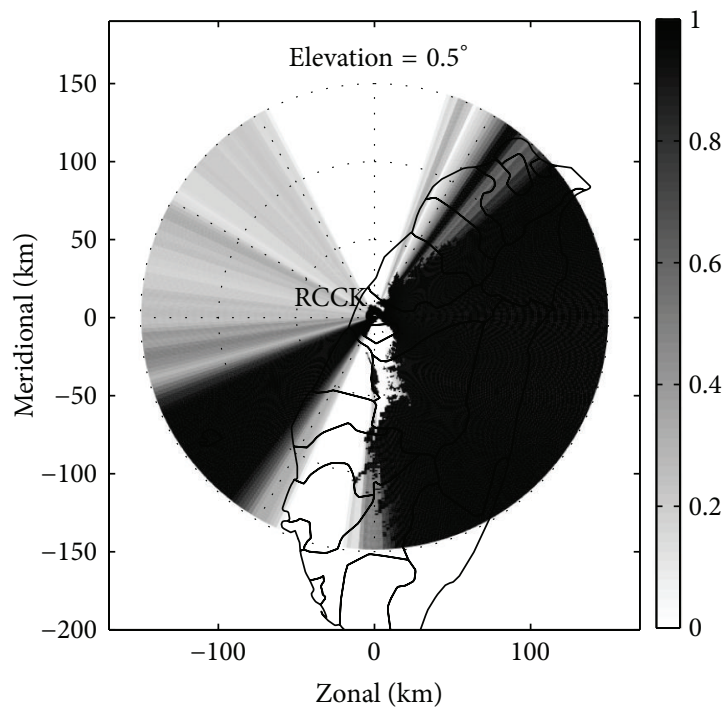

(c)

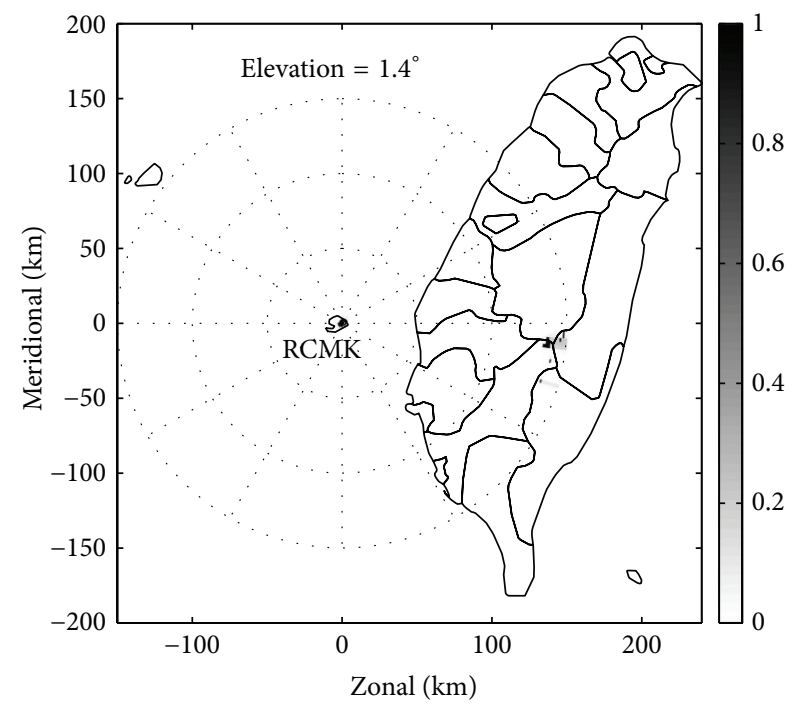

(b)

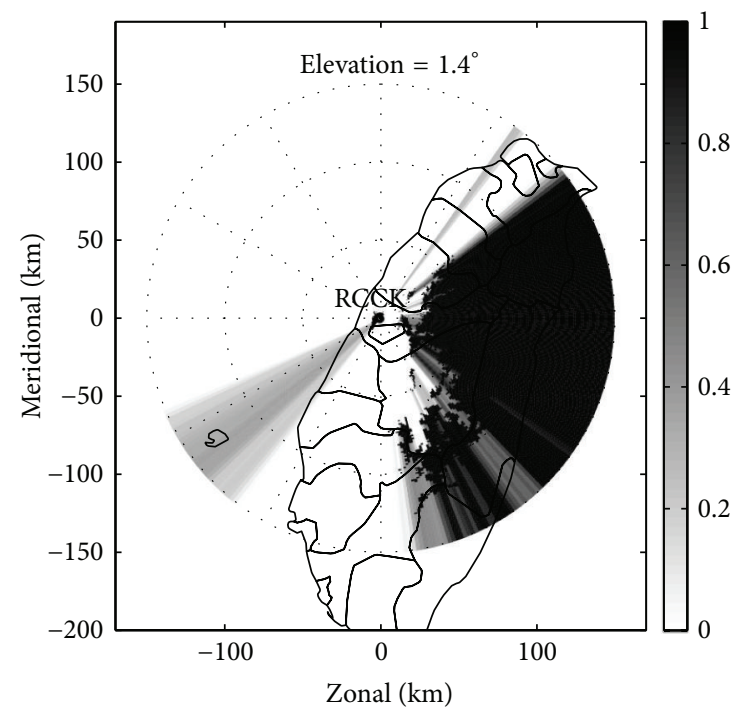

(d)

FIGURE 2: The blockage percentages from the first two tilts of RCMK ( $a$ and b) and RCCK (c and d). The color map indicates the blockage percentages.

shows the blockage percentage maps from the lowest two tilts of RCMK ( $a$ and b) and RCCK (c and d), which were calculated with an approach from Kucera et al. [14] using high-resolution digital elevation model (DEM) data and a standard radar beam propagation model. In radar based QPE, data from the lowest scan is preferred to minimize errors caused by the changes of radar observation with height and horizontal drifts of hydrometeors as they fall to the ground [12]. When the radar data from the lowest tilt is unavailable, the higher tilt data needs to be used in rainfall estimation with proper vertical variation corrections.

2.2. Radar Data Processing. High quality dual-polarized radar data is critical for deriving accurate radar products such as the retrieved drop size distribution, hydrometeor classification, and quantitative precipitation estimation. Since this work investigates the rainfall rate estimation with $K_{\mathrm{DP}}$ and $Z$, the radar data processing in this section mainly focuses on these two variables.

2.2.1. Processing of the Specific Differential Phase Field. In the current work, the polarimetric variables were processed with the Selex-Gematronik's new signal processor (GDRX) developed by SIGMET Inc. [15]. The processes include the $\phi_{\mathrm{DP}}$ unwrapping, $\phi_{\mathrm{DP}}$ fluctuations filtering, and $K_{\mathrm{DP}}$ calculation. A "good" data mask generated along range is first applied on the $\phi_{\mathrm{DP}}$ field to separate the weather echoes from nonweather targets. The "good" data (weather echoes) are associated 


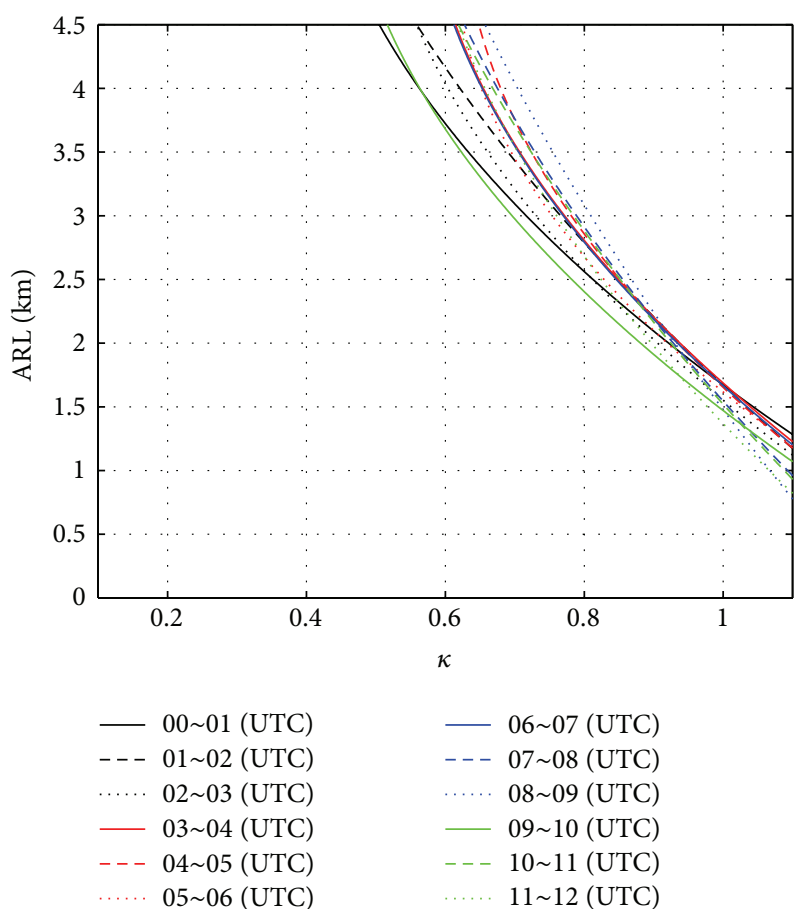

FIGURE 3: The hourly fitted vertical profiles of specific differential phase (VPSDP) results using data of 12 hours (0000 to 1200 UTC on 9 August 2009). The $x$-axis is the normalized VPSDPs, and $y$-axis is the height above radar level.

with a low standard deviation of $\phi_{\mathrm{DP}}$ over 10 gates $\left(\sigma_{\phi_{\mathrm{DP}}}<\right.$ $3^{\circ}$ ), relatively large signal-to-noise ratio (SNR $\left.>15 \mathrm{~dB}\right)$, and large correlation coefficient $\left(\rho_{\mathrm{HV}}>0.9\right)$. The high frequency fluctuations in the processed $\phi_{\mathrm{DP}}$ field (weather echoes) are suppressed with a finite impulse response (FIR) range filter, and the weights of the FIR filter are determined by the desired magnitude response of the filter transfer function. $K_{\mathrm{DP}}$ field is then estimated using the iteratively filtered $\phi_{\mathrm{DP}}$ profile with a "telescoping" method, which calculates the slope of a linear least square fitting using a variable number of gates according to the reflectivity values (10 gates if $Z_{h}>45 \mathrm{dBZ} ; 20$ gates if 35 $<Z_{h}<45 \mathrm{dBZ}$; and 30 gates if $Z_{h}<30 \mathrm{dBZ}$ ) (e.g., $\left.[4,15,16]\right)$. The standard deviation of $K_{\mathrm{DP}}$ could be calculated as [17]

$$
\mathrm{SD}\left(K_{\mathrm{DP}}\right)=\frac{\sqrt{3} \mathrm{SD}\left(\phi_{\mathrm{DP}}\right)}{N^{3 / 2} \Delta},
$$

where $\operatorname{SD}\left(\phi_{\mathrm{DP}}\right)$ is the standard deviation of $\phi_{\mathrm{DP}}, \Delta$ is the range gate space ( $0.5 \mathrm{~km}$ in the current work), and $N$ is the number of range samples in the least squares fit.

Rainfall rates estimated using $K_{\mathrm{DP}}$ have advantages of (1) immunity to calibration errors and attenuation, (2) insensitivity to variations of drop size distributions (DSD), and (3) low sensitivity to partial radar beam blockages [12]. The $R\left(K_{\mathrm{DP}}\right)$ relation is also able to provide more accurate QPE than other estimators during heavy rain events [9]. However, $K_{\mathrm{DP}}$ data may become unavailable when the radar beam is severely or entirely blocked [8]. Higher tilt $K_{\mathrm{DP}}$ data needs to be used in the rainfall rate estimation under

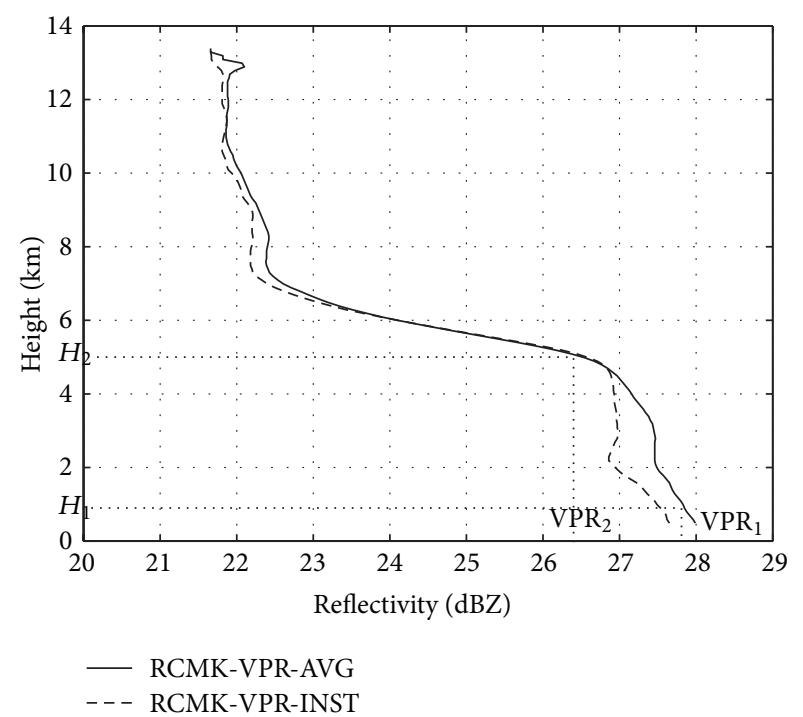

FIGURE 4: The vertical profile of reflectivity obtained on 0320 UTC 9 August 2009. The 1-hour averaged RCMK-VPR-AVG (0220 0320 UTC) and instantaneous RCMK-VPR-INST are presented.

this situation, and a correction for the vertical variation is necessary to achieve accurate estimations. Wang et al. [8] proposed a VPSDP-based correction approach in which a predefined mean VPSDP was determined from 24-hour data and then used to adjust high altitudes $K_{\mathrm{DP}}$ to the ground level (or the radar level, whichever is higher).

In the current work, the VPSDP was derived from 1hour data and was dynamically updated hourly, which could capture temporal variations of VPSDP better than the 24hour mean. Examples of hourly mean VPSDPs from RCMK during Typhoon Morakot (0000 1200 UTC August 9, 2009) are presented in Figure 3, where $y$-axis is the height above radar level (ARL) and the $x$-axis is the normalized vertical profile of $K_{\mathrm{DP}}$. These VPSDPs were computed from $K_{\mathrm{DP}}$ data in a sector of $60^{\circ} \sim 80^{\circ}$ in azimuth and $100 \mathrm{~km} \sim 140 \mathrm{~km}$ in range, where there were no blockages in the lowest tilt. During these 12 hours, wide spread typhoon precipitation covered majority of the radar umbrellas and the hourly VPSDPs showed little changes from hour to hour. All the profiles showed a monotonic increase with decreasing height. The negative slopes of VPSDP are most likely related to the orographic precipitation enhancement associated with the complex terrain in the CMR region. When the atmospheric flow moves over a mountain slope, the forced upward motion enhances the cloud condensation process and produces heavier rain than does the same flow in a flat land. During typhoon landfalls in Taiwan, the steep mountain slope of the CMR, strong winds, and abundant moisture make such orographic enhancement process even more prominent. For these rainfall processes, using $K_{\mathrm{DP}}$ data from high altitudes without the VPSDP correction would result in an underestimation in the radar QPE.

2.2.2. Processing of Reflectivity Field. In reflectivity based rainfall rate estimation algorithm, attenuation correction is 


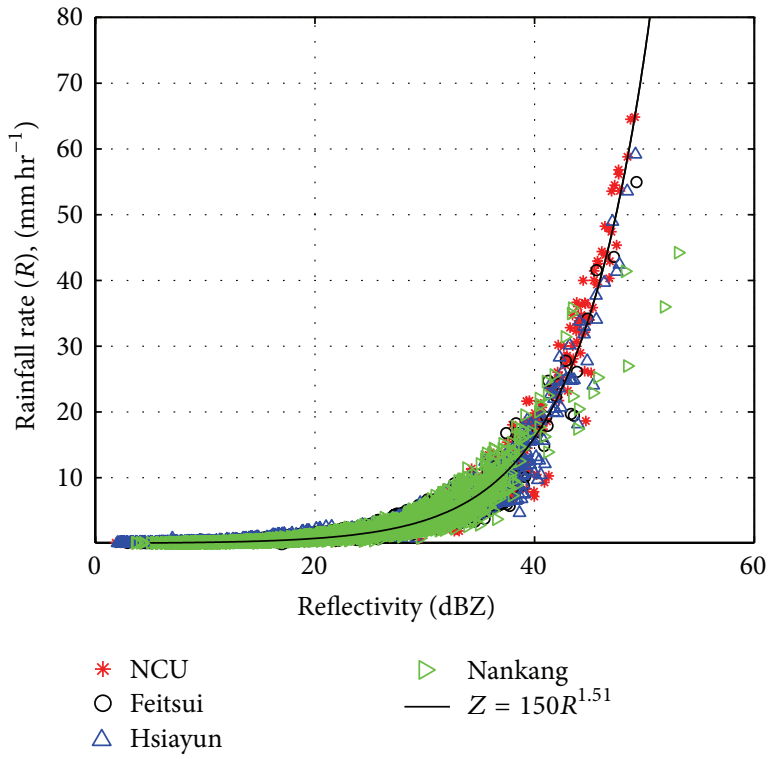

(a)

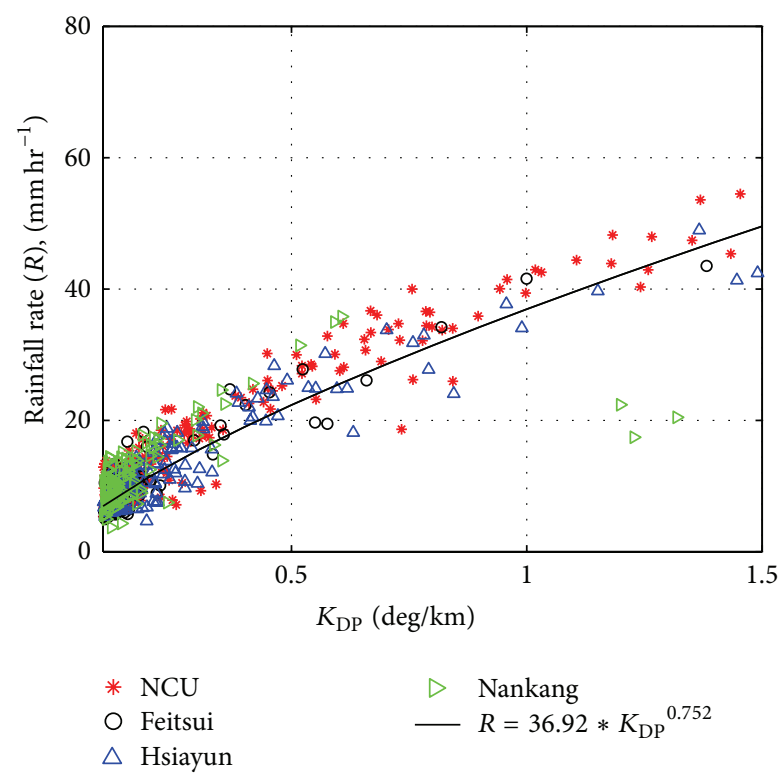

(b)

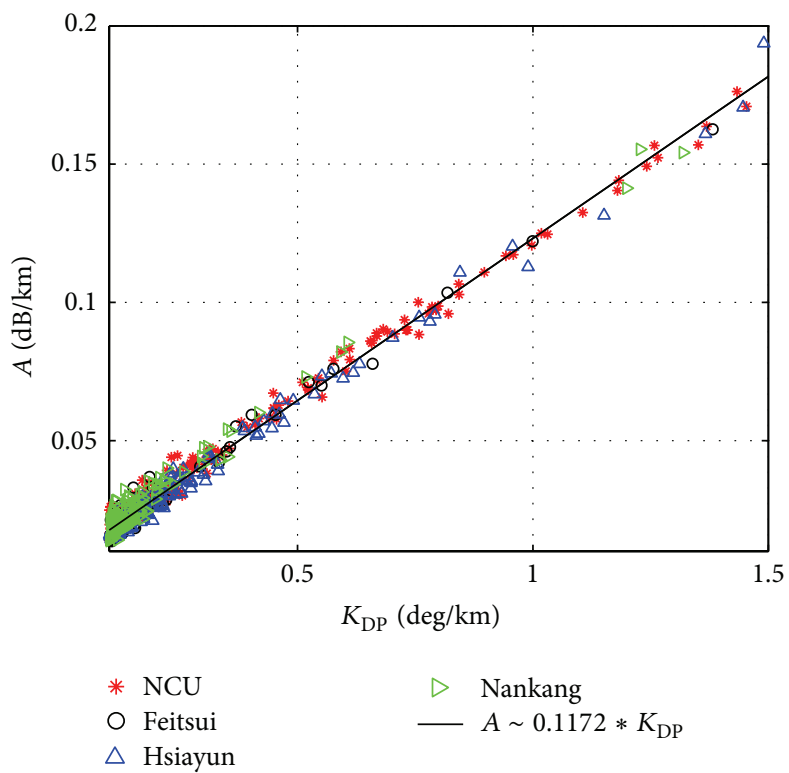

(c)

Figure 5: Scatter plot of (a) $Z$ versus $R$, (b) $K_{\mathrm{DP}}$ versus $R$, and (c) $K_{\mathrm{DP}}$ versus $A$. The scatters were obtained from different JWD observations: red: NCU, black: Feitsui, blue: Hsiayun, and green: Nankang. The polynomial fitted results are inserted as black lines.

a critical issue especially for short wavelength radars such as those of C- and X-band. It was found that approximately $25 \%-45 \%$ underestimation of mean bias resulted when the fixed $Z-R$ relation was used in rainfall rate estimation without attenuation correction for a C-band polarimetric radar [4]. Methods of attenuation correction for reflectivity and differential reflectivity were proposed through the use of differential phase measurements such as the linear $\phi_{\mathrm{DP}}$ method, ZPHI method, and iterative ZPHI method (e.g., [16, 18-20]). The rainfall estimation with corrected $Z$ performed quite well at lower rainfall rate [4]. Because of its simplicity and easy implementation in a real-time system, the linear $\phi_{\mathrm{DP}}$ method was applied in the current work as

$$
\begin{aligned}
Z_{h}(r) & =Z_{h}^{\prime}(r)+2 \alpha \int_{0}^{r} K_{\mathrm{DP}}(s) d s \\
& =Z_{h}^{\prime}(r)+\alpha\left[\phi_{\mathrm{DP}}(r)-\phi_{\mathrm{DP}}(0)\right],
\end{aligned}
$$

where $Z_{h}^{\prime}(r)$ is the observed reflectivity at range $r, Z_{h}(r)$ is the corrected value, $\phi_{\mathrm{DP}}(0)$ is the system $\phi_{\mathrm{DP}}$ value, and $\phi_{\mathrm{DP}}(r)$ is the filtered (by FIR filter) differential phase. It should be noted that the attenuation correction coefficient $\alpha$ depends on DSD, 
DSR, and even temperature variations. The typical range of $\alpha$ is $0.06 \sim 0.08 \mathrm{~dB} \mathrm{deg}^{-1}$ for C-band radars (e.g., $[19,21]$ ). In the current work, the attenuation correction coefficient was derived from local DSD and DSR measurements as shown in Section 3.

Often times, partially and moderately blocked reflectivities are used in rainfall estimation, and underestimations resulted if the power loss is not compensated. In the current work, a power compensation approach developed by Langston and Zhang [22] was implemented to mitigate such errors. The reflectivity is compensated as $z_{\text {corr }}(i, j)=$ $z_{\text {obs }}(i, j) /(1-\operatorname{BLK}(i, j))$, where $z_{\text {corr }}$ and $z_{\text {obs }}$ are the corrected and observed reflectivity in linear unit $\left(\mathrm{mm}^{-6} \mathrm{~m}^{-3}\right)$ and $\operatorname{BLK}(i, j)$ is the two-way beam blockage percentage obtained using the approach developed by Kucera et al. [14]. Only the reflectivities with less than $50 \%$ of blockages are corrected. When the blockage exceeds 50\%, data from the higher tilt where the blockage drops below $50 \%$ is used for rainfall rate estimation. All reflectivity fields implemented in the current work are filtered from ground clutter and wind turbine (e.g., [23]).

The VPR correction scheme in the current work was based on the approach developed by Zhang and Qi [24]. An example of derived VPR from this approach is presented in Figure 4, where the VPRs are derived using the volume scan reflectivity data (after compensation for partial beam blockages) between $20 \mathrm{~km}$ and $80 \mathrm{~km}$ from RCMK. In this example, two VPRs were generated and presented: the instantaneous VPR (RCMK-VPR-INST) at 0550 UTC, and the 1hour average VPR (RCMK-VPR-AVG) in the range 0450 0550 UTC 9 August 2009. The reflectivity field from higher tilt was corrected from the vertical variation with RCMK-VPRAVG as

$$
z^{\text {corrected }}\left(H_{1}\right)=z^{\text {original }}\left(H_{2}\right) \frac{\mathrm{VPR}_{1}^{\text {linear }}}{\mathrm{VPR}_{2}^{\text {linear }}},
$$

where $z\left(H_{2}\right)$ and $z\left(H_{1}\right)$ are the reflectivity in linear unit $\left(\mathrm{mm}^{-6} \mathrm{~m}^{3}\right)$ from $\mathrm{H}_{2}$ (ground level or the radar level, whichever is higher) and the $H_{1}$ (height of radar beam), respectively. $\mathrm{VPR}_{1,2}^{\text {linear }}$ are the derived VPRs in linear unit $\left(\mathrm{mm}^{-6} \mathrm{~m}^{3}\right)$. The corrected reflectivity in $\mathrm{dBZ}$ is therefore calculated as $z^{\text {corrected }}\left(H_{1}\right)=10 \log _{10}\left(z^{\text {corrected }}\left(H_{1}\right)\right)$.

\section{Drop Size Distribution (DSD) and Drop Shape Relation (DSR) Measurements}

The attenuation correction coefficient $(\alpha)$ and the rainfall rate estimators (specifically, $R(Z)$ and $R\left(K_{\mathrm{DP}}\right)$ ) were derived based on local DSD and DSR measurements. Four impacttype Joss-Waldvogel disdrometers (JWDs) (as indicated in Figure 1), with the measurement range $0.359 \mathrm{~mm} \sim 5.373 \mathrm{~mm}$ of 20 bins and temporal resolution of 1 minute, were used to obtain the DSD during warm seasons. A total of 7920 minutes of DSD data were used in the current work, and those data included mei-yu precipitations (during May 2012) and typhoon precipitations (during August 2012). Reflectivities and rainfall rates were estimated from the measured DSD,

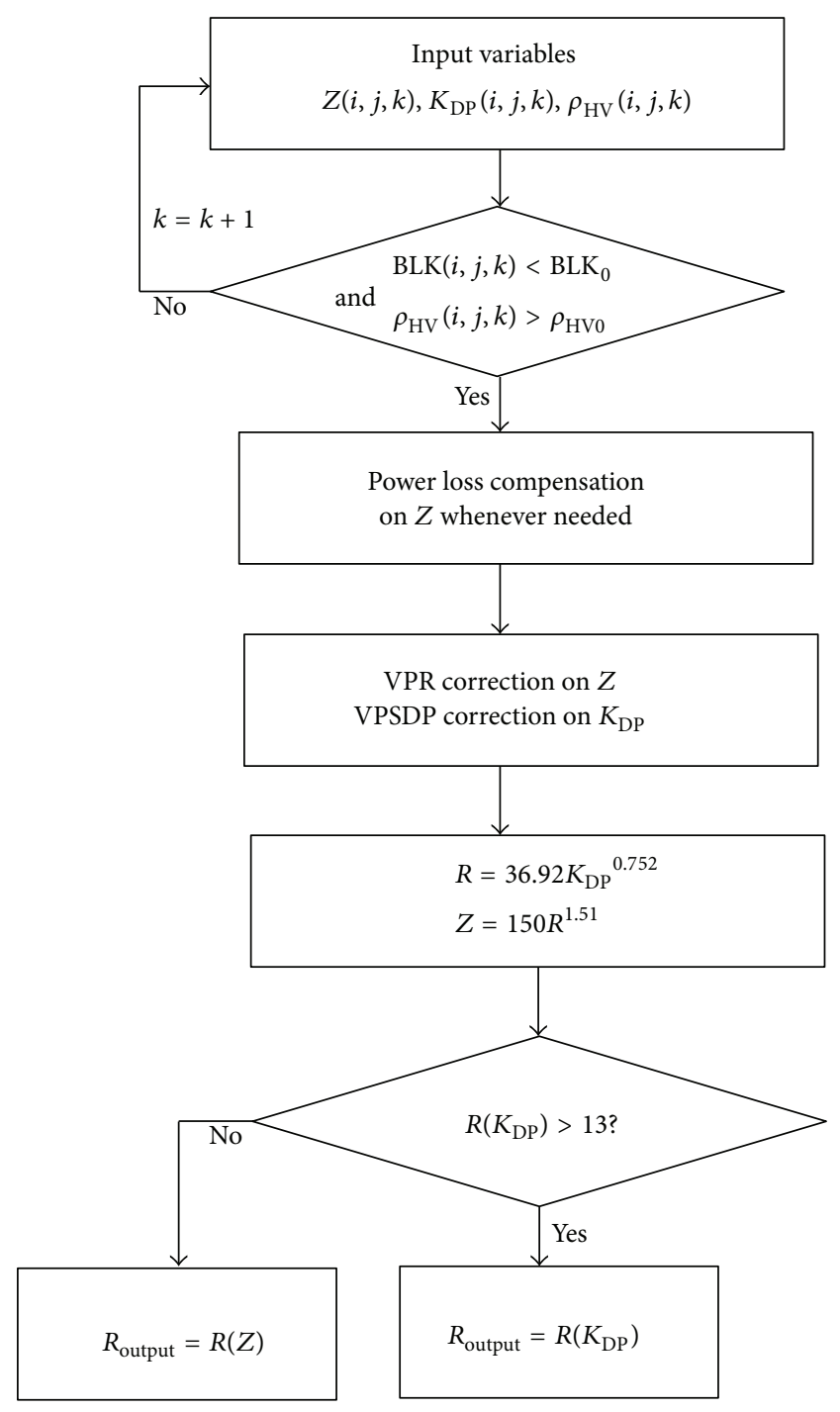

FIGURE 6: The block diagram of the vertical corrected composite algorithm.

and an $R(Z)$ relationship was derived through a least square fitting method. Figure 5(a) shows the scatter plot of the $R-Z$ pairs and the fitted $R(Z)$ relationship.

The DSR used in the current work was measured with a 2D video disdrometer (2DVD) during typhoon landfalls [25]. Chang et al. [25] found that the raindrops in typhoon precipitations are more spherical than raindrops in typical maritime or continental precipitations systems, and this unique characteristic was considered as a feature of terraininfluenced convective systems during typhoon landfalls. The specific attenuation $A$ and $K_{\mathrm{DP}}$ were calculated using the local measured DSD and DSR proposed by Chang et al. [25] through a T-matrix method. The scatter plots of $R$ $K_{\mathrm{DP}}$ and $A-K_{\mathrm{DP}}$ pairs are presented in Figures 5(b) and 5(c); the attenuation correction coefficient $\alpha=0.1172 \mathrm{~dB} / \mathrm{deg}$ and the relation of $R=36.92 K_{\mathrm{DP}}^{0.752}$ were estimated through a least squares fitting approach. The obtained $\alpha$ and 


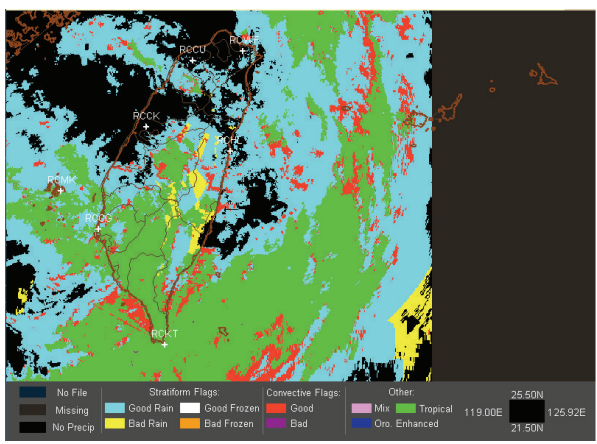

(a)

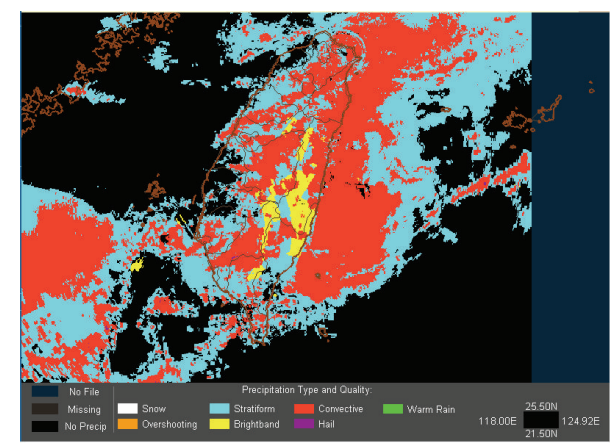

(b)

FIGURE 7: The precipitation classification result from (a) typhoon precipitation (0600 UTC 9 August 2009) and (b) mei-yu precipitation (0300 UTC 12 June 2012). The cyan, red, and green colors indicate the precipitation category is classified as stratiform, convective, and tropical precipitation.

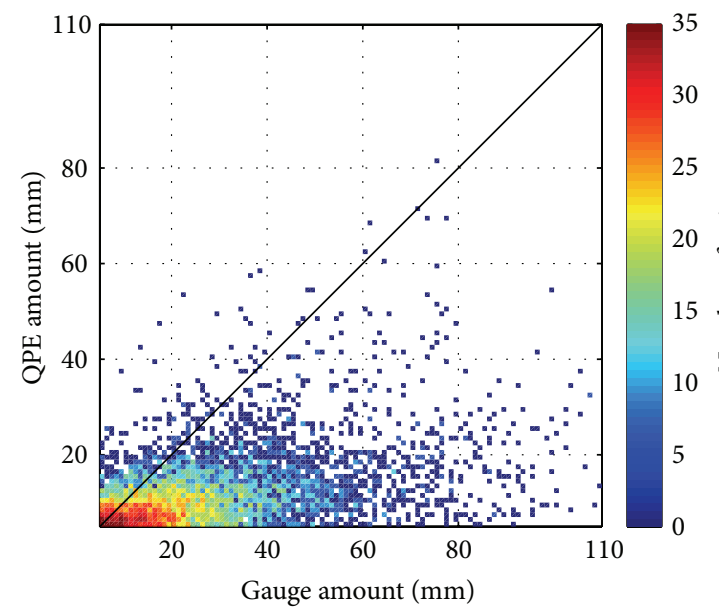

(a)

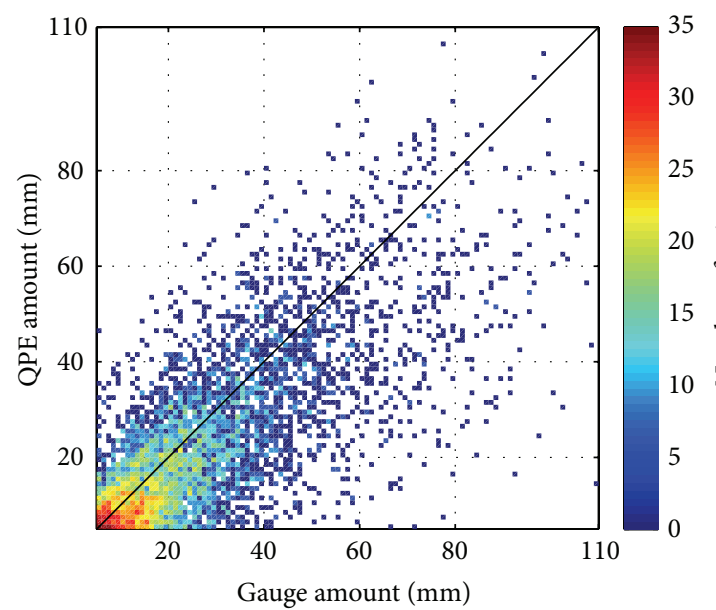

(c)

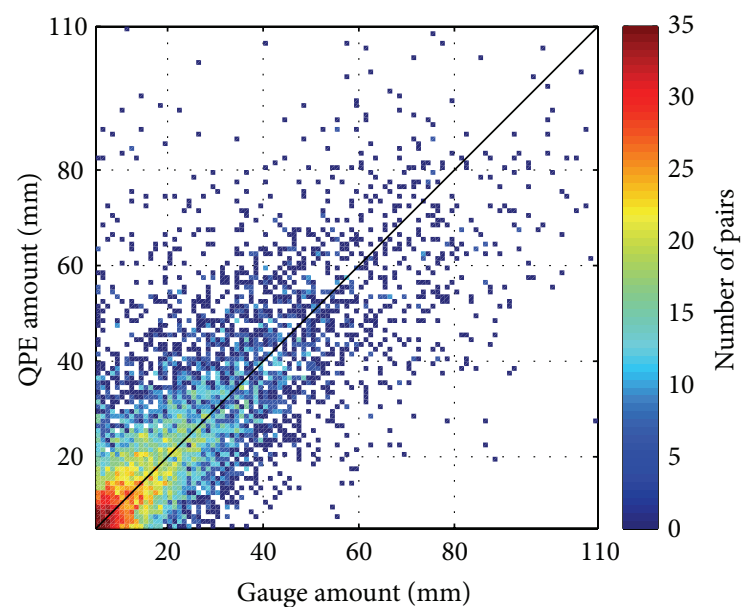

(b)

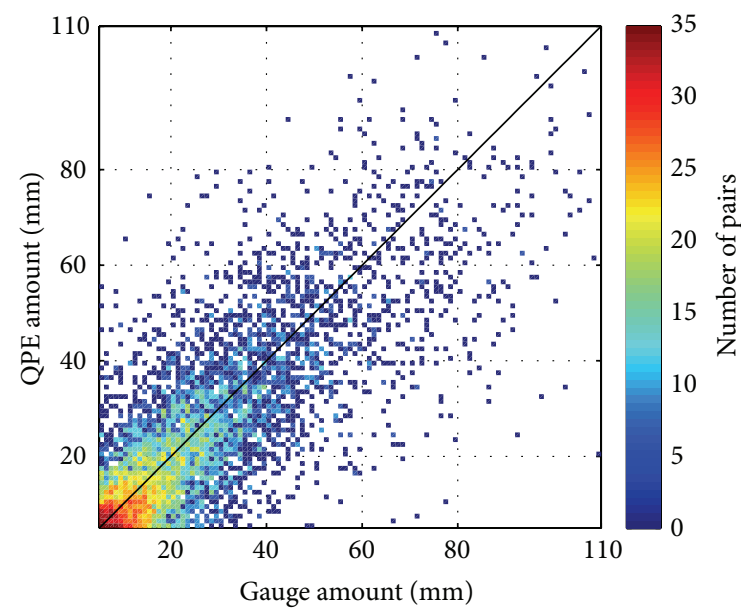

(d)

FIGURE 8: The comparison results between gauge network observations and QPE using (a) RZ, (b) RKDP, (c) CA, and (d) VCCA. 72-hour data from typhoon Morakot (08/08/2009 08/09/2009) and Fanapi (09/19/2010) are selected, and a total of 17090 QPE-gauge pairs are used in the analysis. 


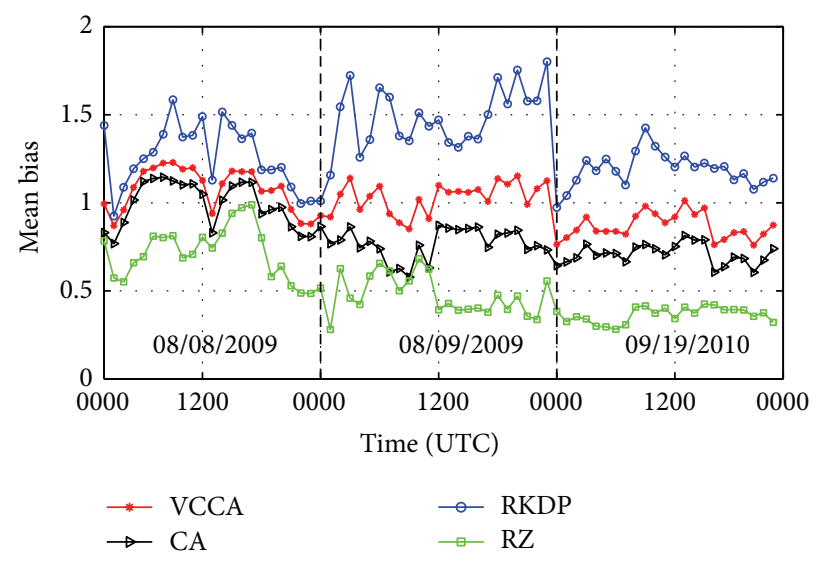

(a)

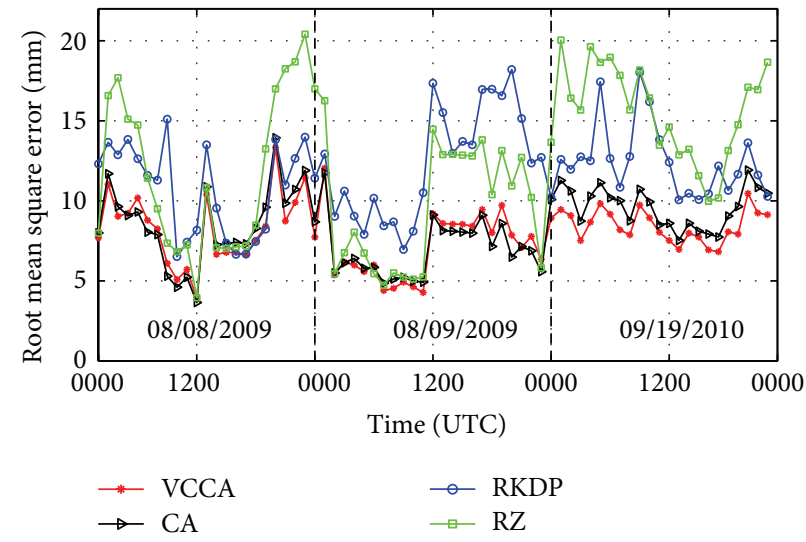

(b)

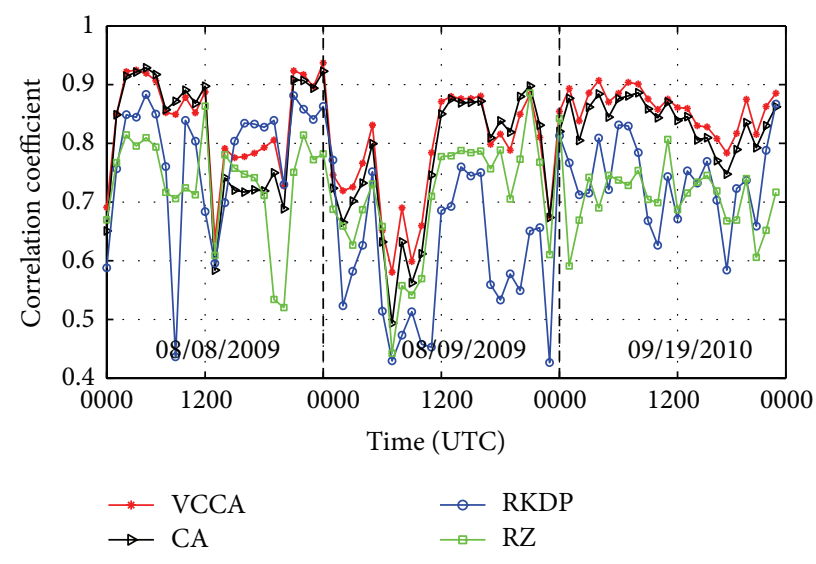

(c)

FigurE 9: The time series plots of mean bias (a), root mean square error (b), and correlation coefficient (c) using these four approaches.

$R\left(K_{\mathrm{DP}}\right)$ relations are very close to the results presented by Wang et al. [8], where the same DSR relation and simulated DSD were used. Although the impact of the DSD on the polarimetric variables (specifically the $K_{\mathrm{DP}}$ and $A$ ) cannot be ignored, the $R\left(K_{\mathrm{DP}}\right)$ and $R(A)$ relations are less sensitive to the variations of DSD than $R(Z)$ relation. Note that all four JWDs and the 2DVD located in the northern part of Taiwan (Figure 1). Therefore, the derived $R-Z, R-K_{\mathrm{DP}}$ relations and the attenuation correction coefficient are most representative of precipitation processes in northern Taiwan.

\section{Vertically Corrected Composite Algorithm (VCCA)}

Figure 6 shows the flowchart of the VCCA algorithm developed in the current work. It was similar to the composite algorithm developed by Bringi et al. [4] with the addition of VPR and VPSDP corrections into the rainfall rate estimation. Another main difference is that the specific differential reflectivity was not used in the current rainfall rate estimation. Even though specific differential reflectivity was used in previous synthetic/composite algorithms [4, 9], it was excluded in the current work because of the following concerns: (1) The $Z_{\mathrm{DR}}$-based rainfall estimation algorithm is generally more sensitive to uncompensated rain path and wet radome attenuation effects [21], (2) $Z_{\mathrm{DR}}$-based rainfall estimation is highly sensitive to $Z_{\mathrm{DR}}$ errors (e.g., a $0.1 \mathrm{~dB}$ error in $Z_{\mathrm{DR}}$ would result in a $10 \%$ error in rain rate when using the $R\left(Z, Z_{\mathrm{DR}}\right)$ relation), and (3) due to significant blockages by the CMR, the lower tilts $Z_{\mathrm{DR}}$ data become unavailable (unreliable) and the higher tilts $Z_{\mathrm{DR}}$ data need to be used. However, vertical variations of $Z_{\mathrm{DR}}$ in different precipitation regimes have not been investigated at the current stage, and a direct use of the high tilt $Z_{\mathrm{DR}}$ could introduce unknown biases in rainfall rate estimation. Future work will study potential applications of $Z_{\mathrm{DR}}$ in automated identifications of different precipitation regimes and provide guidance for using adaptive $R(Z)$ and $R\left(K_{\mathrm{DP}}\right)$ relations in the real-time radar QPE.

The VCCA workflow starts with the raw polarimetric radar fields of the horizontal reflectivity $Z(i, j, k)$, specific differential phase $K_{\mathrm{DP}}(i, j, k)$, and cross correlation coefficient $\rho_{\mathrm{HV}}(i, j, k)$, where $i, j$, and $k$ are radar bin indices along azimuth, range, and elevation directions. The two-way beam blockage percentage, $\operatorname{BLK}(i, j, k)$, is then calculated using high-resolution DEM data and the $4 / 3$ effective earth radius 


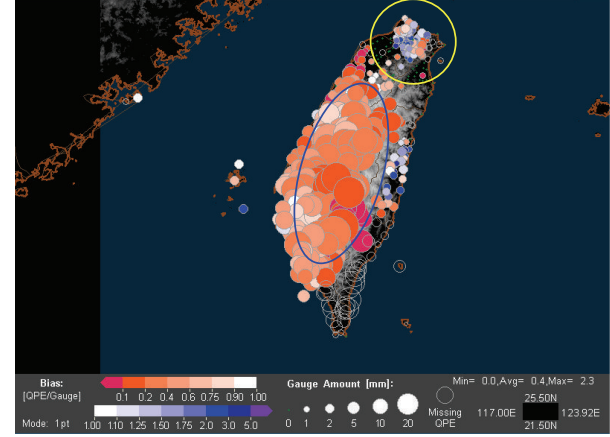

(a)

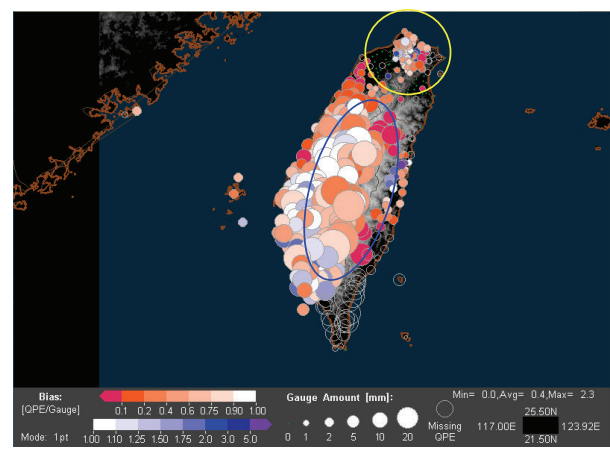

(c)

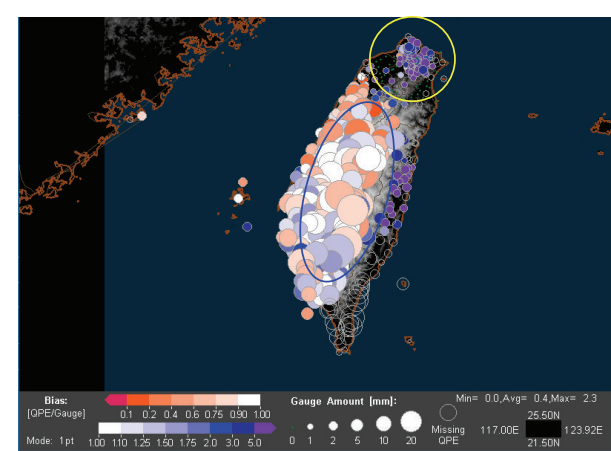

(b)

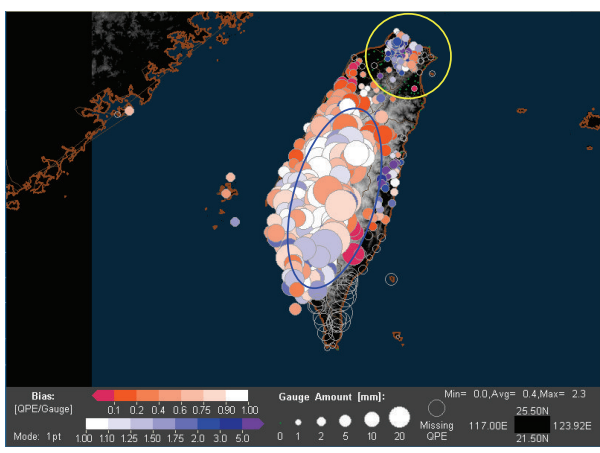

(d)

FIGURE 10: Comparison of the ratio of QPEs/gauges from (a) RZ, (b) RKDP, (c) CA, and (d) VCCA approaches. One-hour accumulated precipitation in the range 2000 2100 UTC 8 August 2009 is used in the evaluation. The size of the circles represents the gauge observed rainfall amount and the color shows the ratio: the warm (orange), cold (blue), and white colors indicate underestimation, overestimation, and accurate estimation, respectively.

model for the radar beam propagation [26]. For any given radar bin, if $\operatorname{BLK}(i, j, k)$ is larger than predefined threshold $\mathrm{BLK}_{0}(50 \%)$, or the cross correlation coefficient is less than $\rho_{\mathrm{HV} 0}(0.8)$, then the $Z, K_{\mathrm{DP}}$, and $\rho_{\mathrm{HV}}$ from same azimuth $(i)$ and range $(j)$ at the adjacent higher elevation angle $(k+1)$ are used as a new input. Otherwise, the attenuation correction and partial beam blockage compensation are applied to the reflectivity $(Z(i, j, k))$ field if deemed necessary. Further, the $Z\left(K_{\mathrm{DP}}\right)$ field is corrected with the VPR (VPSDP) correction method, and the rain rate is then calculated using either $R(Z)$ or $R\left(K_{\mathrm{DP}}\right)$ depending on the intensity of the rain at the given location. A threshold of $13 \mathrm{~mm} \mathrm{hr}^{-1}$ (Figure 6) is adopted from Bringi et al. [4] to determine whether $R(Z)$ or $R\left(K_{\mathrm{DP}}\right)$ shall be applied. Although different thresholds such as $10 \mathrm{~mm} \mathrm{hr}^{-1}$ and $15 \mathrm{~mm} \mathrm{hr}^{-1}$ were tried, no significant improvements were obtained.

\section{Performance Evaluation}

The VCCA was evaluated with three cases of a total of 240hour precipitation. Case I consists of 72-hour data from two typhoon precipitation systems during 2009 and 2010; case II consists of 48-hour data from mei-yu precipitation in 2012; case III consists of 5 days of precipitation during summer season in 2011. Most of the precipitation in case I was classified as tropical type. The precipitation in case II was largely convective mixed with stratiform. Case III was dominated by stratiform precipitation with small sporadic convective cells.

Four different QPE approaches were evaluated using these three cases, all of which used the quality controlled polarimetric variables (such as the attenuation correction and power compensation from partial beam blockages). The four approaches were (1) with the relation of $Z=150 R^{1.51}$ only (RZ); (2) with the relation of $R=36.92 K_{\mathrm{DP}}^{0.752}$ only (RKDP); (3) with the combination of $R(Z)$ and $R\left(K_{\mathrm{DP}}\right)(\mathrm{CA})$; and (4) with the approach proposed in Section 4 (VCCA). The $Z\left(K_{\mathrm{DP}}\right)$ field in approaches RZ, RKDP, and VCCA was corrected with VPR (VPSDP) methods, and the approach CA is similar to the proposed approach VCCA, but higher tilt $Z\left(K_{\mathrm{DP}}\right)$ values were directly used in the rainfall rate estimation without the VPR (VPSDP) correction. Rain rate field from each radar was calculated and then mosaicked onto a regional Cartesian grid. The rain rate fields were then aggregated into hourly accumulations and compared with gauge network observations. Details of the mosaic procedure can be found in Wang et al. [8]. Three scores were used to assess the performance of each algorithm: (1) the mean bias $(\mathrm{MB}), \mathrm{MB}=\left\langle R_{p}\right\rangle /\left\langle G_{p}\right\rangle,(2)$ the root mean square error (RMSE), RMSE $=\left\langle\left(R_{p}-G_{p}\right)^{2}\right\rangle^{1 / 2}$, and (3) correlation 


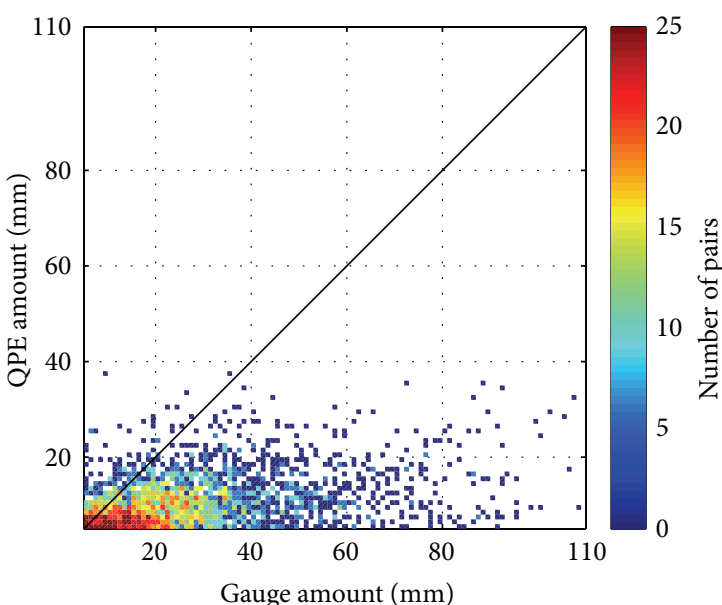

(a)

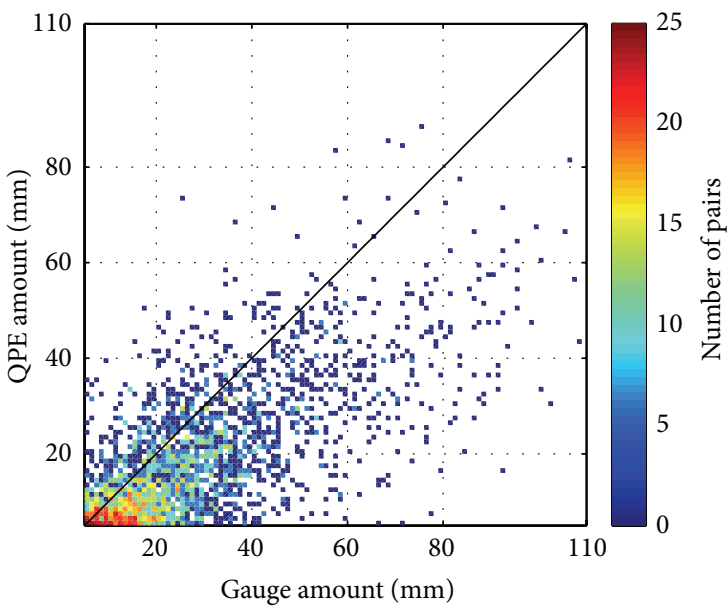

(c)

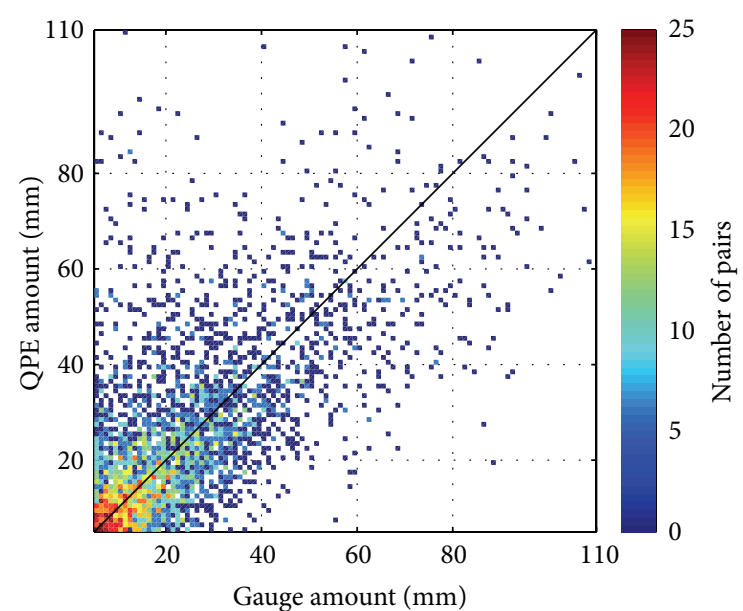

(b)

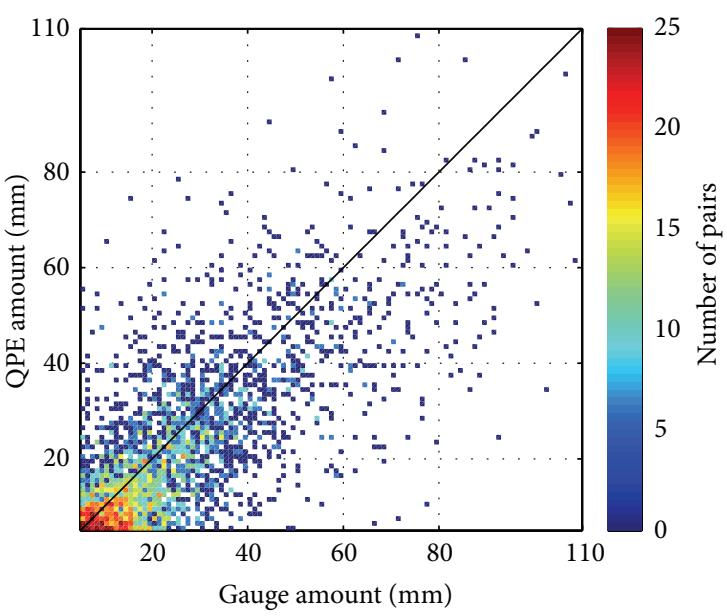

(d)

FIGURE 11: Similar to Figure 8, only those QPE-gauge pairs in which gauge's heights are $500 \mathrm{~m}$ or higher above sea level are selected. There are a total of 6276 QPE-gauge pairs used in this plot.

coefficient (CC), $\mathrm{CC}=\left\langle\left(R_{p}-\left\langle R_{p}\right\rangle\right)\left(G_{p}-\left\langle G_{p}\right\rangle\right)\right\rangle / \sigma_{R} \sigma_{G}$, where $R_{p}$ and $G_{p}$ are the 1-hour radar and gauge accumulated rainfall for each pair $(p)$ and $\sigma_{R}\left(\sigma_{G}\right)$ is the standard deviation of all the radar (gauge) pairs.

Case I. Typhoons, considered as one of the worst threats to eastern Pacific, usually bring significant precipitations to land masses and lead to large losses of properties and lives. In Taiwan region, the landfalls of typhoon Morakot (Fanapi) produced peak rainfall rate of $136 \mathrm{~mm} \mathrm{hr}^{-1}\left(124.5 \mathrm{~mm} \mathrm{hr}^{-1}\right)$ with heavy precipitations during 8 9 August 2009 (19 September 2010). Following the approach proposed by $\mathrm{Xu}$ et al. [27], most precipitation of these two events was classified as tropical, which indicated a significantly heavier rainfall than the stratiform and convective systems with the same reflectivity. An example of the classification result at 0600 UTC 9 August 2009 is shown in Figure 7, where the light green, cyan, and red colors represent tropical, stratiform, and convective precipitation, respectively.
Hourly rainfall accumulations from the four approaches of RZ, RKDP, CA, and VCCA were calculated and compared with gauge network observations. The scatter plot of comparison results is presented in Figure 8, where a total of 17090 QPE-gauge pairs are used in this statistical analysis and the density of the occurrence is displayed with different colors. The statistical scores are also included in Table 2. Significant underestimation $(\mathrm{MB}=0.44, \mathrm{RMSE}=13.93 \mathrm{~mm}$, and $\mathrm{CC}=$ $0.67)$ resulted from the $R Z$ approach. Several factors that could result in the underestimation included wet radome, improper $R-Z$ relation, inadequate attenuation correction, and/or insufficient power compensation [8]. In this work, the $R-Z$ relation was fitted to the JWD observations in northern Taiwan, which might have not represented the DSD in the core of the typhoon that was located in the CMR region. Additional drop size distribution observations in the CMR are needed to further understand the spatial variation of microphysical processes in Taiwan. Overestimation $(\mathrm{MB}=$ $1.22, \mathrm{RMSE}=12.31 \mathrm{~mm}$, and $\mathrm{CC}=0.73$ ) was obtained using 
TABLE 2: The statistical scores of mean bias $(\mathrm{MB})$, root mean square error (RMSE), and correlation coefficient (CC) obtained from two typhoons (72-hour data), one mei-yu (48 hours data), and longterm stratiform precipitation (120-hour data). The results from four approaches are included; they are $R(Z)$ only, $R\left(K_{\mathrm{DP}}\right)$ only, combination of $R\left(K_{\mathrm{DP}}\right)$ and $R(Z)$ without vertical correction (CA), and the vertically corrected composite algorithm (VCCA).

\begin{tabular}{lcccc}
\hline & Case I & Case II & Case III & Total \\
\hline RZ & & & & \\
MB & 0.44 & 0.54 & 0.60 & $\mathbf{0 . 5 6}$ \\
RMSE $(\mathrm{mm})$ & 13.93 & 8.1 & 5.84 & $\mathbf{8 . 9 6}$ \\
CC & 0.67 & 0.60 & 0.68 & $\mathbf{0 . 7 0}$ \\
RKDP & & & & \\
MB & 1.22 & 1.12 & 1.07 & $\mathbf{1 . 2 4}$ \\
RMSE (mm) & 12.31 & 9.17 & 5.78 & $\mathbf{9 . 9 6}$ \\
CC & 0.73 & 0.56 & 0.73 & $\mathbf{0 . 7 1}$ \\
RZ + RKDP & & & & \\
MB & 0.76 & 0.80 & 0.78 & $\mathbf{0 . 8 2}$ \\
RMSE (mm) & 9.15 & 7.07 & 4.93 & $\mathbf{6 . 9 6}$ \\
CC & 0.83 & 0.67 & 0.78 & $\mathbf{0 . 8 1}$ \\
VCCA & & & & \\
MB & 0.92 & 0.89 & 0.85 & $\mathbf{0 . 9 6}$ \\
RMSE (mm) & 8.28 & 7.03 & 4.75 & $\mathbf{6 . 5 6}$ \\
CC & 0.85 & 0.69 & 0.79 & $\mathbf{0 . 8 4}$ \\
\hline
\end{tabular}

the approach of RKDP only. Although RKDP was shown to produce relatively accurate rainfall estimation at heavy rain (Figure $8(\mathrm{~b})$ ), large overestimations were produced at the low end of accumulations. Examinations of the $K_{\mathrm{DP}}$ fields in the typhoon events revealed that low signal-tonoise ratios in light rain resulted in noisy $K_{\mathrm{DP}}$ values and subsequently inaccurate rainfall estimation. On the other hand, $Z$ field is relatively smooth and stable even in light rain, and rain rate variations among different $R(Z)$ relations are much less at low reflectivities than at high reflectivities. The composite algorithms (approaches 3 and 4) take the advantages of $\mathrm{RZ}$ in the light rain (less noises in $Z$ field and less uncertainties in $R(Z)$ ) and RKDP in the heavy rain (better correspondence of $K_{\mathrm{DP}}$ to water mass than $Z$ ). As expected, they produced more accurate rainfall estimation than using only RZ or RKDP. The composite algorithm with vertical variation correction (VCCA) performed even better than CA in the three scores MB: 0.92 versus $0.76(\sim 17 \%$ improvement), RMSE: $8.28 \mathrm{~mm}$ versus 9.15 (approximately $10 \%$ improvement), and CC: 0.85 versus 0.83 (approximately $2 \%$ improvement). The improvements were due to the fact that there existed large vertical variations in $K_{\mathrm{DP}}$ and $Z$ field (Figures 3 and 4 ), and the variations were not accounted for in the CA method. Both $K_{\mathrm{DP}}$ and $Z$ profiles showed a clear decreasing trend with the increasing height (Figures 3 and 4 ). When the higher tilt $K_{\mathrm{DP}}$ and $Z$ values are used in the rainfall rate estimation, an underestimation bias would result if the vertical variations were not corrected.

The time series plots of MB, RMSE, and CC are presented in Figure 9, where different colors represent results from
TABLE 3: Similar to Table 2, only those QPE-gauge pairs in which the gauge's heights are $500 \mathrm{~m}$ or higher above sea level are used in the statistical analysis.

\begin{tabular}{lcccc}
\hline & Case I & Case II & Case III & Total \\
\hline RZ & & & & \\
MB & 0.37 & 0.47 & 0.51 & $\mathbf{0 . 4 0}$ \\
RMSE (mm) & 17.02 & 8.87 & 6.60 & $\mathbf{1 3 . 7}$ \\
CC & 0.62 & 0.62 & 0.72 & $\mathbf{0 . 6 4}$ \\
RKDP & & & & \\
MB & 1.12 & 1.10 & 0.95 & $\mathbf{1 . 1 0}$ \\
RMSE (mm) & 14.07 & 10.80 & 6.51 & $\mathbf{1 2 . 1}$ \\
CC & 0.69 & 0.47 & 0.71 & $\mathbf{0 . 7 0}$ \\
RZ + RKDP & & & & \\
MB & 0.60 & 0.67 & 0.67 & $\mathbf{0 . 6 1}$ \\
RMSE (mm) & 11.94 & 7.79 & 5.31 & $\mathbf{1 0 . 0}$ \\
CC & 0.79 & 0.66 & 0.80 & $\mathbf{0 . 7 9}$ \\
VCCA & & & & \\
MB & 0.85 & 0.81 & 0.75 & $\mathbf{0 . 8 2}$ \\
RMSE (mm) & 10.36 & 7.35 & 5.00 & $\mathbf{8 . 6}$ \\
CC & 0.81 & 0.66 & 0.85 & $\mathbf{0 . 8 1}$ \\
\hline
\end{tabular}

different approaches. The VCCA produced more close to unit $\mathrm{MB}$ and CC, and lower RMSE comparing to other three approaches. The enhancements are especially obvious for the case of typhoon Fanapi (09/19/2010) because of the more significant vertical variations in the $Z$ and $K_{\mathrm{DP}}$ fields. To demonstrate the spatial distribution of the comparison result, an example of the ratios of QPEs/gauges (at 2100 UTC 8 August 2009) is also shown in Figure 10. The size of the circle indicates the precipitation amount observed by a gauge, and color indicates the ratio of QPE-gauge. Obvious overestimations are found from the north of Taiwan (within the yellow circle) using RKDP approach (Figure 10(b)), and the $\mathrm{RZ}$ provides better estimation comparing to the RKDP approach. The performances of these two approaches in this region further demonstrate that $\mathrm{RZ}$ is a more proper estimator for light rain (around $5 \mathrm{~mm} / \mathrm{hr}$ ) than RKDP. On the other hand, within the core of the typhoon (within the blue circle), the RKDP produces good estimation and RZ produce apparent underestimation. The composite algorithm (CA and VCCA) can take advantages of RZ and RKDP and produce accurate estimations for light and heavy rains. The VCCA can further enhance the QPE through correcting the vertical variations in $K_{\mathrm{DP}}$ and $Z$ field, and the obtained MB, RMSE, and $C C$ are 0.91 versus $0.74,8.0$ versus 9.1, and 0.90 versus 0.88 , respectively.

The statistics were also calculated for gauges located at $500 \mathrm{~m}$ above MSL or higher (mainly in the CMR region) to assess the impact of VPR and VPSDP corrections in the $\mathrm{CMR}$ region. The scatter plot and scores for the specific gauge group are presented in Figure 11 and Table 3. The mean bias ratios for the CA dropped $21 \%$ from 0.76 to 0.6 , indicating a much larger underestimation in the radar QPE in the CMR region than in other regions. The VPR/VPSDP correction showed a significant improvement and recovered 29\% of 


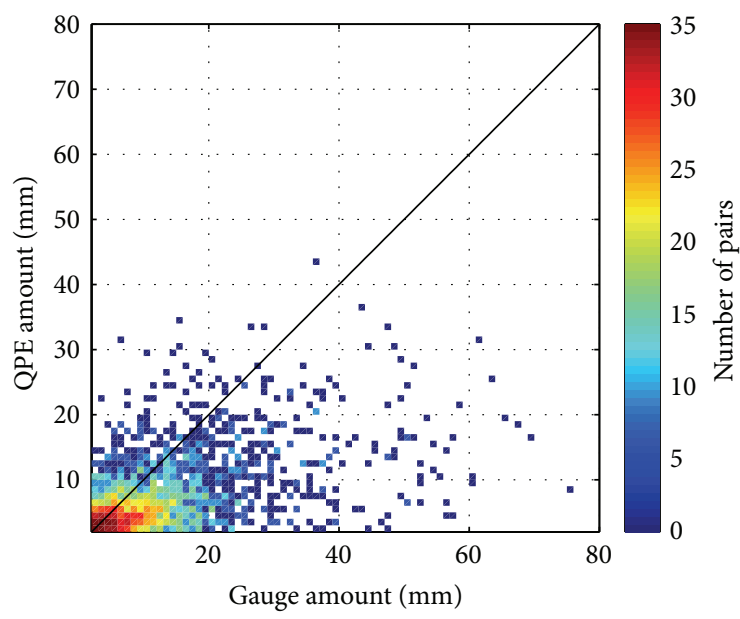

(a)

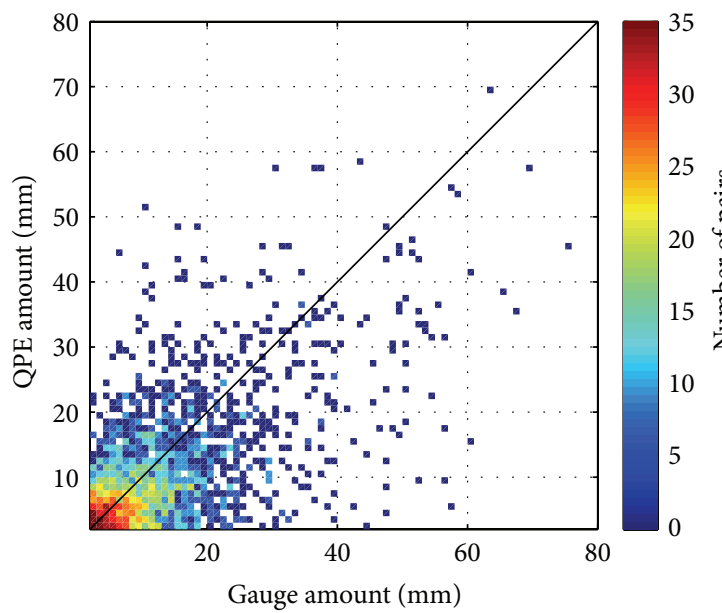

(c)

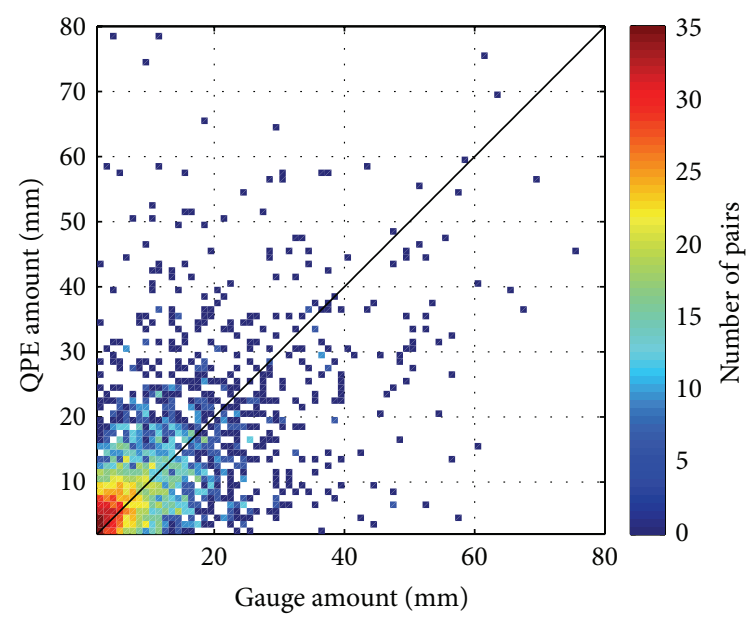

(b)

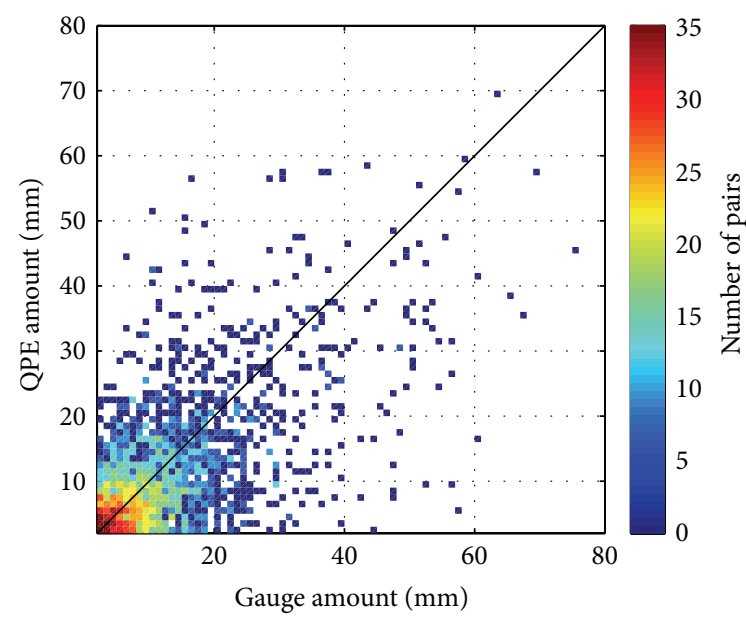

(d)

FIGURE 12: The comparison results between gauge network observations and QPE using (a) RZ, (b) RKDP, (c) CA, and (d) VCCA. 48-hour data from mei-yu precipitation (13 14 June 2012) are selected, and a total of 4017 QPE-gauge pairs are used in the analysis.

the underestimation $(0.85$ versus 0.6$)$. This is better than the $17 \%$ reduction in the mean bias ratio for the whole domain. There was also a $13 \%$ reduction in the RMSE $(11.9 \mathrm{~mm}$ versus $10.3 \mathrm{~mm}$ ) by using VCCA instead of CA, which is larger than the $10 \%$ reduction for the whole domain. These scores indicated the importance of the VPR and VPSDP corrections in the CMR region. Without the corrections, the orographic enhanced rainfall would not be accounted for and large underestimation errors would occur. The improvement in the correlation coefficient brought by the VCCA versus CA $(0.81$ to 0.79 ) was relatively small.

Case II. The period from mid-May to mid-June is called meiyu season in Taiwan, and the mei-yu front normally brings heavy precipitation to Taiwan [28]. The mei-yu precipitation studied in the current work had a mix of convective and stratiform as shown in Figure 7(b). Two days (13 14 June 2012) of radar QPEs were calculated using the four approaches, and hourly accumulations were compared with gauge observations. Similar to case I, the QPE-gauge pairs with gauge height of above MSL (4017 pairs) and above $500 \mathrm{~m}$ of MSL (1665 pairs) were used in the analysis. The scatter plots and three statistical scores are presented in Figures 12 and 13, and Tables 2 and 3, respectively. With the VPR and VPSDP corrections, VCCA improved the radar QPE over CA in $\mathrm{MB}$ (approximately 10\%) and RMSE (approximately 5\%) for all the gauges, and in MB (approximately 17\%) and RMSE (approximately 5.6\%) for those gauges located at places with the terrain higher than $500 \mathrm{~m}$ above MSL.

Case III. The four approaches were also assessed using 5 days (11 15 July 2011) of precipitation during the summer season. Scatter plots and the three scores of 1-hour radar QPE accumulations versus the gauge observations are presented in Figure 14 and Tables 2 and 3. For these events, the VCCA still performed the best among all four approaches. However, the impact of the VPR and VPSDP corrections seemed to be less predominant than they were for the typhoon and mei-yu events because of the smaller vertical variations in $Z$ and $K_{\mathrm{DP}}$ field. 


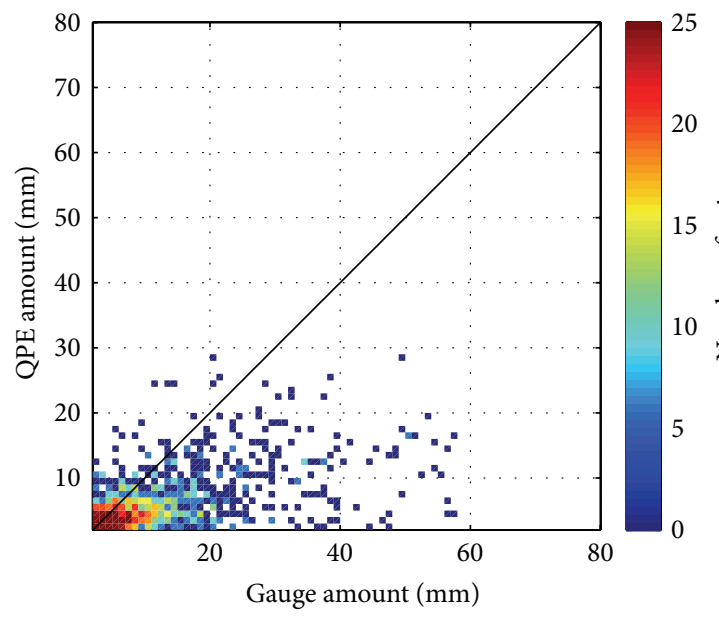

(a)

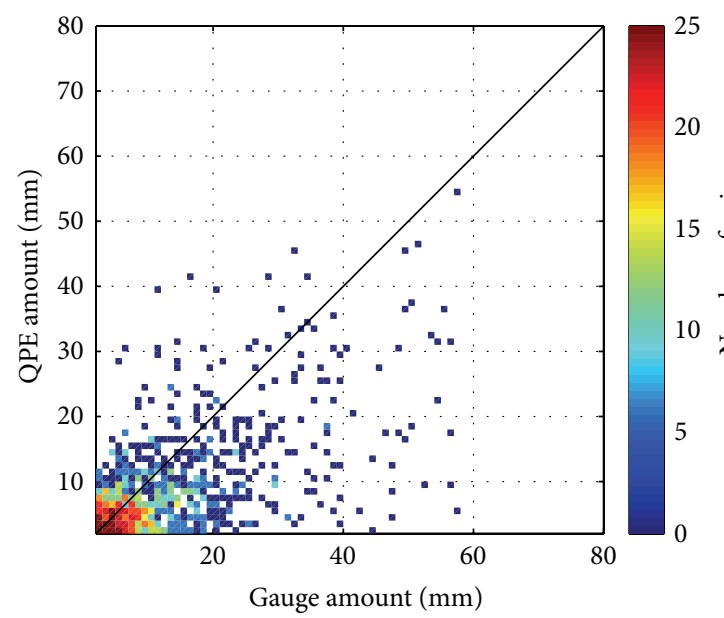

(c)

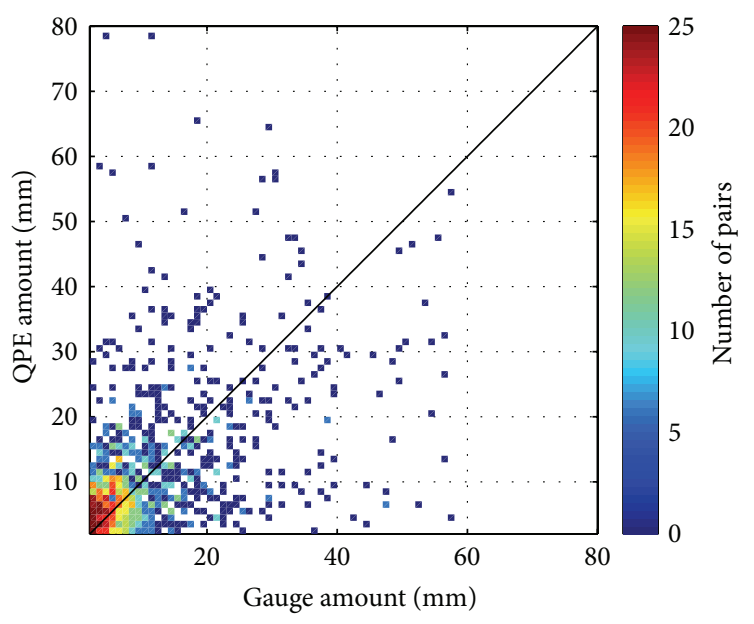

(b)

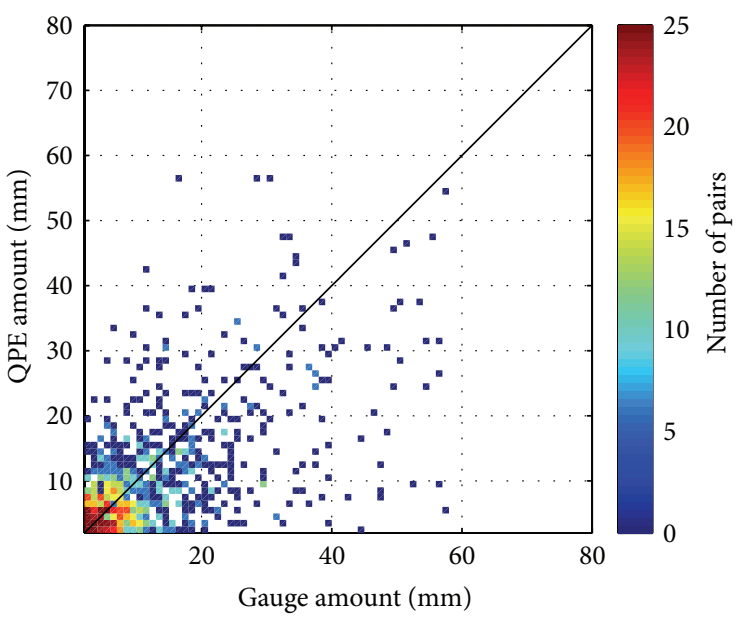

(d)

FIGURE 13: Similar to Figure 12, only those QPE-gauge pairs in which gauge's heights are $500 \mathrm{~m}$ or higher above sea level are selected. There are a total of 1665 QPE-gauge pairs used in this plot.

\section{Summary and Conclusion}

The reasons causing the biases in radar based QPE are complex. Different factors could directly/indirectly affect the QPE result, such as the radar calibration, contamination from bright band, presence of hail, and improper rainfall estimator. This work attempts to address two important issues in radar based QPE: the radar beam blockage and the selection of optimal rainfall rate estimators. When radar beams at low tilts are blocked due to the complex terrains, the high tilt data is used in the rainfall estimated to achieve whole radar coverage QPE. To avoid the biases caused by the vertical variations in precipitation system, techniques of VPR and VPSDP were proposed in previous studies to correct the vertical variations in radar observations, and the resulted rainfall estimations were enhanced with the corrected radar variables. In the research of the rainfall rate estimators, the synthetic/composite algorithms were designed for a more accurate rainfall estimation through automatically selecting the optimal rainfall rate estimator according to the rain intensity. It was shown that the synthetic/composite algorithm produced the most accurate rainfall estimation compared to other algorithms implementing single radar variable. In the current work, a vertically corrected composite algorithm (VCCA) was proposed for a further enhancement of the rainfall estimation in complex terrain. With the proposed new approach, the higher tilt reflectivity (specific differential phase) was corrected from VPR (VPSDP-based) correction approach, and the corrected variables were then implemented in the rainfall estimation. The new approach and other estimators were evaluated with different cases from the recent three years with a total of 240 hours of data. The precipitation types in the evaluation include stratiform, convective, and tropical precipitation systems. Overall, compared to the composite approach, the vertically corrected composite algorithm produced significantly enhanced QPE results in mean bias (approximately 25\% improvement), root mean square error (approximately 14\% improvement), and correlation coefficient (2\%). 


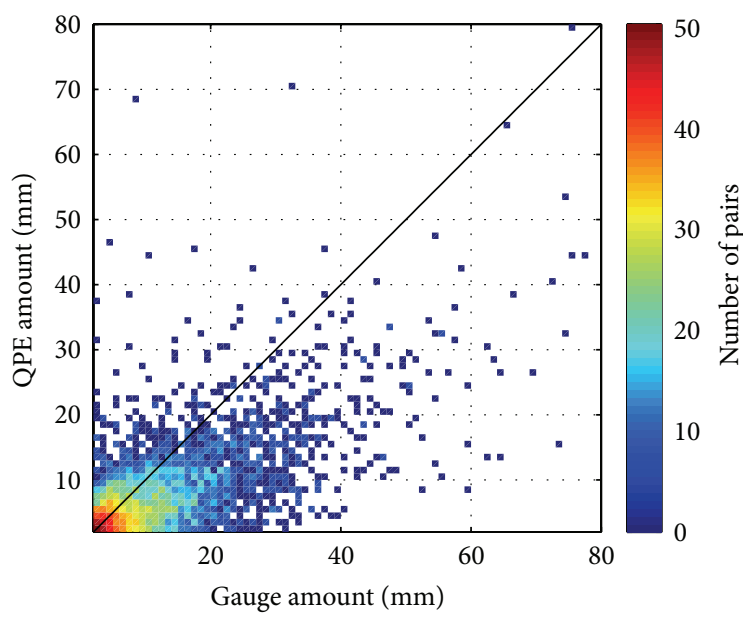

(a)

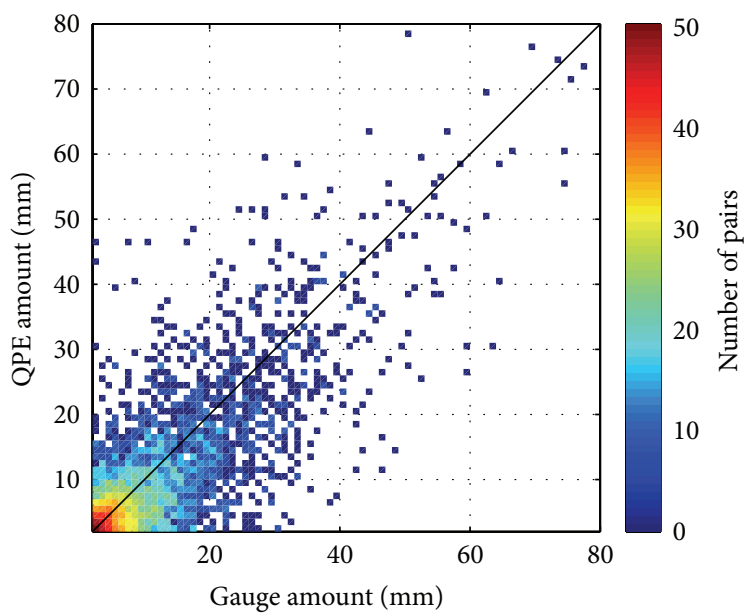

(c)

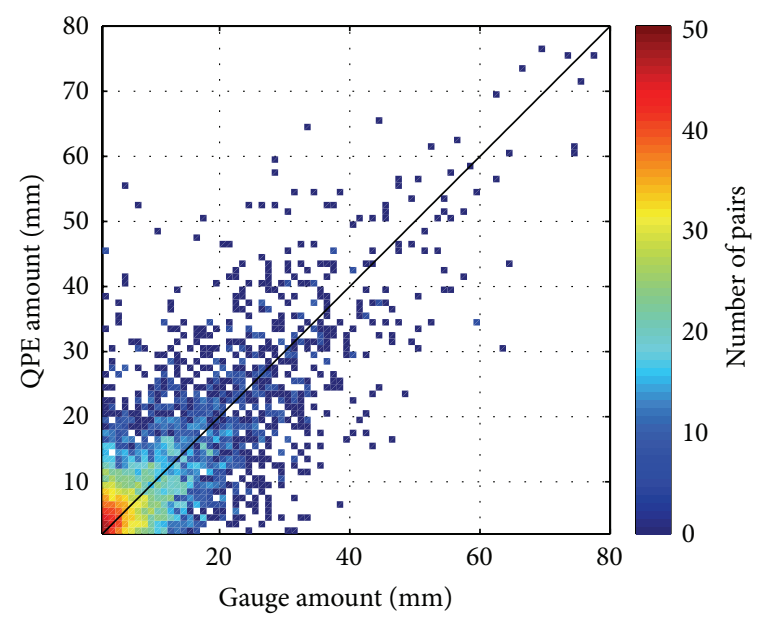

(b)

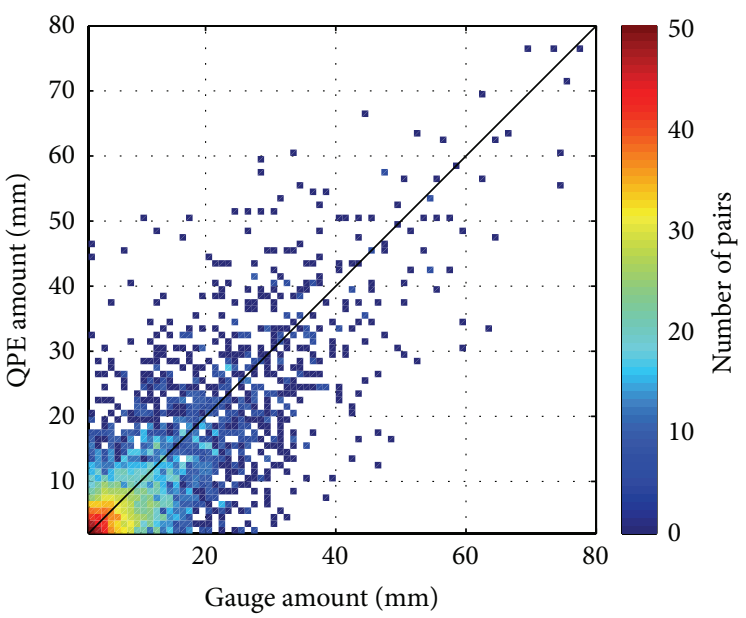

(d)

FIGURE 14: The comparison results between gauge network observations and QPE using (a) RZ, (b) RKDP, (c) CA, and (d) VCCA. 5-day data from summer precipitation (11 15 July 2011) are selected, and a total of 6885 QPE-gauge pairs are used in the analysis.

\section{Conflict of Interests}

The authors declare that there is no conflict of interests regarding the publication of this paper.

\section{Acknowledgments}

This research is supported by funding from the Central Weather Bureau of Taiwan, Republic of China, and was provided by NOAA/Office of Oceanic and Atmospheric Research under NOAA-University of Oklahoma Cooperative Agreement no. NA110AR4320072, US Department of Commerce. The authors would like to thank Professor PayLiam Lin of National Central University for providing the $2 \mathrm{D}$ video disdrometer data and Dr. Pengfei Zhang provided many helpful comments and that greatly improved the paper.

\section{References}

[1] A. C. Schroth, M. S. Chandra, and P. F. Mesichner, "A C-band coherent polarimetric radar for propagation and cloud physics research," Journal of Atmospheric and Oceanic Technology, vol. 5, no. 6, pp. 803-822, 1988.

[2] A. V. Ryzhkov, T. J. Schuur, D. W. Burgess, and D. S. Zrnic, "Polarimetric tornado detection," Journal of Applied Meteorology, vol. 44, no. 5, pp. 557-570, 2005.

[3] J. J. Gourley, P. Tabary, and J. P. du Chatelet, "Data quality of the Meteo-France C-band polarimetric radar," Journal of Atmospheric and Oceanic Technology, vol. 23, no. 10, pp. 13401356, 2006.

[4] V. N. Bringi, M. A. Rico-Ramirez, and M. Thurai, "Rainfall estimation with an operational polarimetric C-band radar in the United Kingdom: comparison with a gauge network and error analysis," Journal of Hydrometeorology, vol. 12, no. 5, pp. 935-954, 2011.

[5] R. D. Palmer, D. Bodine, M. Kumjian et al., "Observations of the 10 May 2010 tornado outbreak using OU-PRIME: potential for new science with high-resolution polarimetric radar," Bulletin of the American Meteorological Society, vol. 92, no. 7, pp. 871-891, 2011.

[6] A. V. Ryzhkov and D. S. Zrnic, "Assessment of rainfall measurement that uses specific differential phase," Journal of Applied Meterology, vol. 35, no. 11, pp. 2080-2090, 1996. 
[7] E. A. Brandes, A. V. Ryzhkov, and D. S. Zrnić, "An evaluation of radar rainfall estimates from specific differential phase," Journal of Atmospheric and Oceanic Technology, vol. 18, no. 3, pp. 363375,2001

[8] Y. Wang, J. Zhang, A. V. Ryzhkov, and L. Tang, "C-band polarimetric radar QPE based on specific differential propagation phase for extreme typhoon rainfall," Journal of Atmospheric and Oceanic Technology, vol. 30, no. 7, pp. 1354-1370, 2013.

[9] A. V. Ryzhkov, S. E. Giangrande, and T. J. Schuur, "Rainfall estimation with a polarimetric prototype of WSR-88D," Journal of Applied Meteorology, vol. 44, no. 4, pp. 502-515, 2005.

[10] Y. Qi and J. Zhang, "Correction of radar QPE errors associated with low and partially observed brightband layers," Journal of Hydrometeorology, vol. 14, no. 6, pp. 1933-1943, 2013.

[11] Y. Qi, J. Zhang, B. Kaney, C. Langston, and K. Howard, "Improving WSR-88D radar QPE for orographic precipitation using profiler observations," Journal of Hydrometeorology, vol. 15, no. 3, pp. 1135-1151, 2014.

[12] D. S. Zrnić and A. Ryzhkov, "Advantages of rain measurements using specific differential phase," Journal of Atmospheric and Oceanic Technology, vol. 13, no. 2, pp. 454-464, 1996.

[13] K. Friedrich, U. Germann, J. J. Gourley, and P. Tabary, "Effects or radar beam shielding on rainfall estimation for the polarimetric C-band radar," Journal of Atmospheric and Oceanic Technology, vol. 24, no. 11, pp. 1839-1859, 2007.

[14] P. A. Kucera, W. F. Krajewski, and C. B. Young, "Radar beam occultation studies using GIS and DEM technology: an example study of Guam," Journal of Atmospheric and Oceanic Technology, vol. 21, no. 7, pp. 995-1006, 2004.

[15] V. N. Bringi, M. Thurai, and R. Hannesen, Dual-Polarization Weather Radar Handbook, Selex-Gematronik, Neuss, Germany, 2nd edition, 2005.

[16] S.-G. Park, M. Maki, K. Iwanami, V. N. Bringi, and V. Chandrasekar, "Correction of radar reflectivity and differential reflectivity for rain attenuation at X-band. Part II. Evaluation and application," Journal of Atmospheric and Oceanic Technology, vol. 22, no. 11, pp. 1633-1655, 2005.

[17] N. Balakrishnan and D. S. Zrnic, "Estimation of rain and hail rates in mixed-phase precipitation," Journal of the Atmospheric Sciences, vol. 47, no. 5, pp. 565-583, 1990.

[18] A. R. Jameson, "The effect of temperature on attenuation correction schemes in rain using polarization propagation differential phase shift," Journal of Applied Meteorology, vol. 31, no. 9, pp. 1106-1118, 1992.

[19] L. D. Carey, S. A. Rutledge, D. A. Ahijevych, and T. D. Keenan, "Correcting propagation effects in C-band polarimetric radar observations of tropical convection using differential propagation phase," Journal of Applied Meteorology, vol. 39, no. 9, pp. 1405-1433, 2000.

[20] J. Testud, E. L. Bouar, E. Obligis, and M. Ali-Mehenni, "The rain profiling algorithm applied to polarimetric weather radar," Journal of Atmospheric and Oceanic Technology, vol. 17, no. 3, pp. 332-356, 2000.

[21] G. Vulpiani, M. Montopoli, L. D. Passeri, A. G. Gioia, P. Giordano, and F. S. Marzano, "On the use of dual-polarized c-band radar for operational rainfall retrieval in mountainous areas," Journal of Applied Meteorology and Climatology, vol. 51, no. 2, pp. 405-425, 2012.

[22] C. Langston and J. Zhang, "An automated algorithm for radar beam occultation," in Proceedings of the 11th Conference on
Aviation, Range and Aerospace Meteorology (ARAM '04), CDROM, pp. 5-16, American Meteorological Society, Hyannis, Mass, USA, October 2004.

[23] F. Kong, Y. Zhang, and R. Palmer, "Wind turbine clutter mitigation for weather radar by adaptive spectrum processing," in Proceedings of the IEEE Radar Conference: Ubiquitous Radar (RADARCON '12), pp. 0471-0474, Atlanta, Ga, USA, May 2012.

[24] J. Zhang and Y. Qi, "A real-time algorithm for the correction of brightband effects in radar-derived QPE," Journal of Hydrometeorology, vol. 11, no. 5, pp. 1157-1171, 2010.

[25] W.-Y. Chang, T.-C. C. Wang, and P.-L. Lin, "Characteristics of the raindrop size distribution and drop shape relation in typhoon systems in the western Pacific from the $2 \mathrm{D}$ video disdrometer and NCU C-band polarimetric radar," Journal of Atmospheric and Oceanic Technology, vol. 26, no. 10, pp. 19731993, 2009.

[26] R. J. Doviak and D. S. Zrnic, Doppler Radar and Weather Observations, Academic Press, 2nd edition, 1993.

[27] X. Xu, K. Howard, and J. Zhang, "An automated radar technique for the identification of tropical precipitation," Journal of Hydrometeorology, vol. 9, no. 5, pp. 885-902, 2008.

[28] C.-S. Chen and Y.-L. Chen, "The precipitation characteristics of Taiwan," Monthly Weather Review, vol. 131, pp. 1324-1341, 2003. 

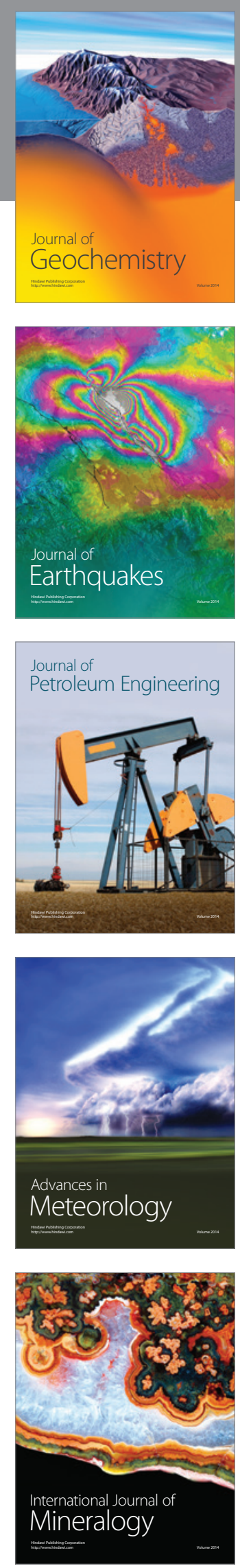
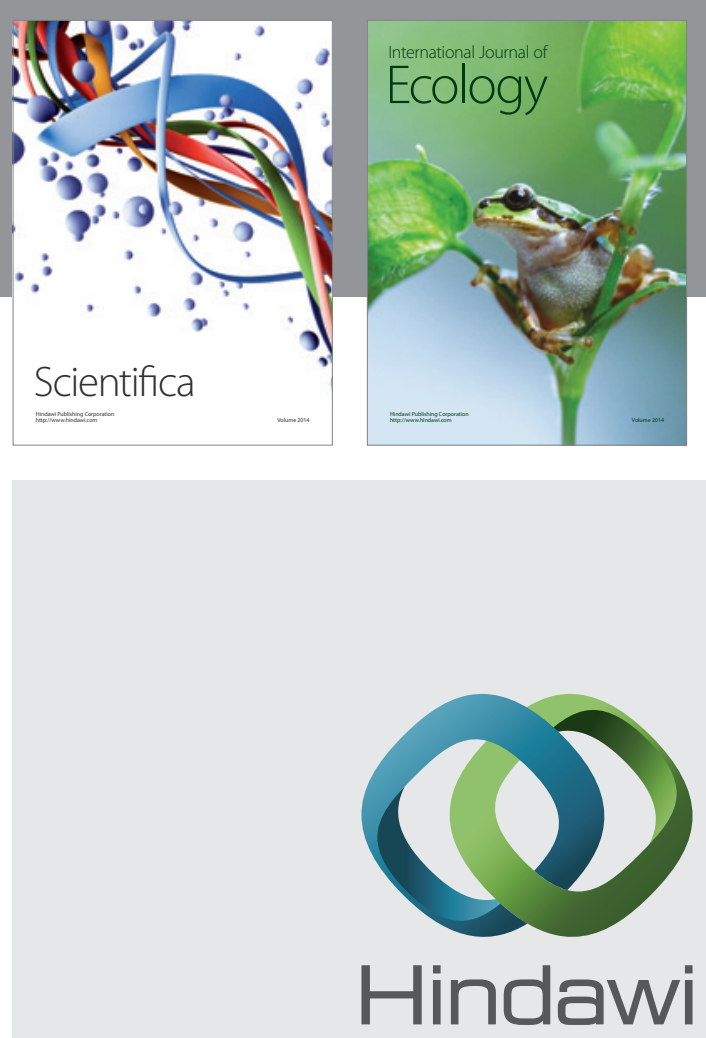

Submit your manuscripts at

http://www.hindawi.com
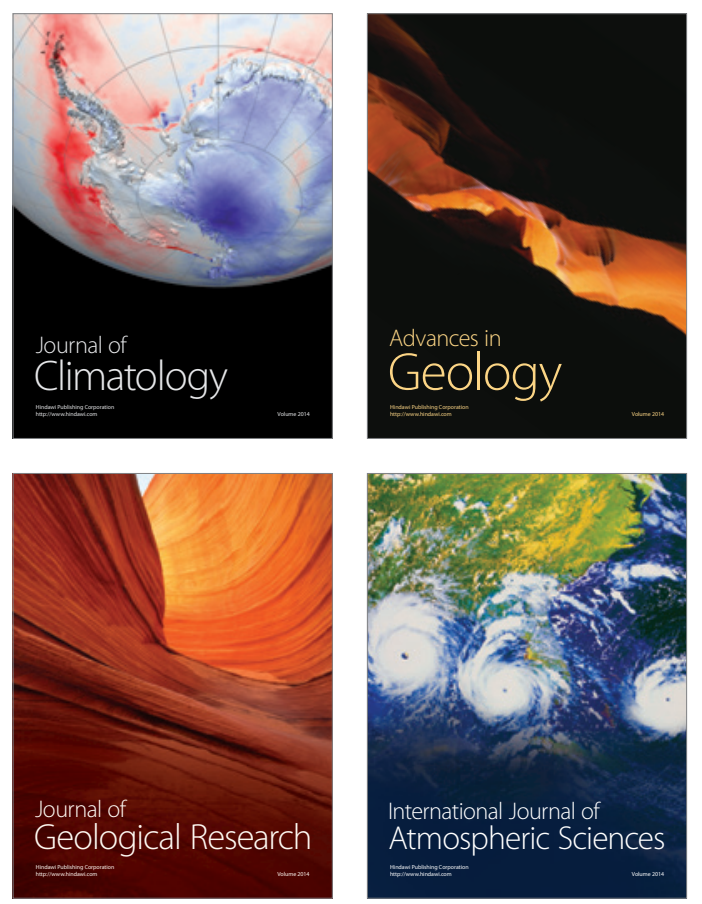

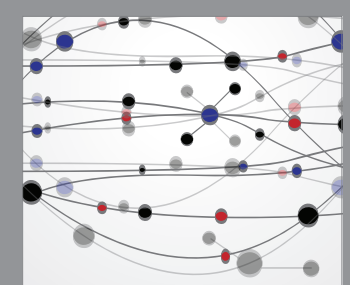

The Scientific

\section{World Journal}
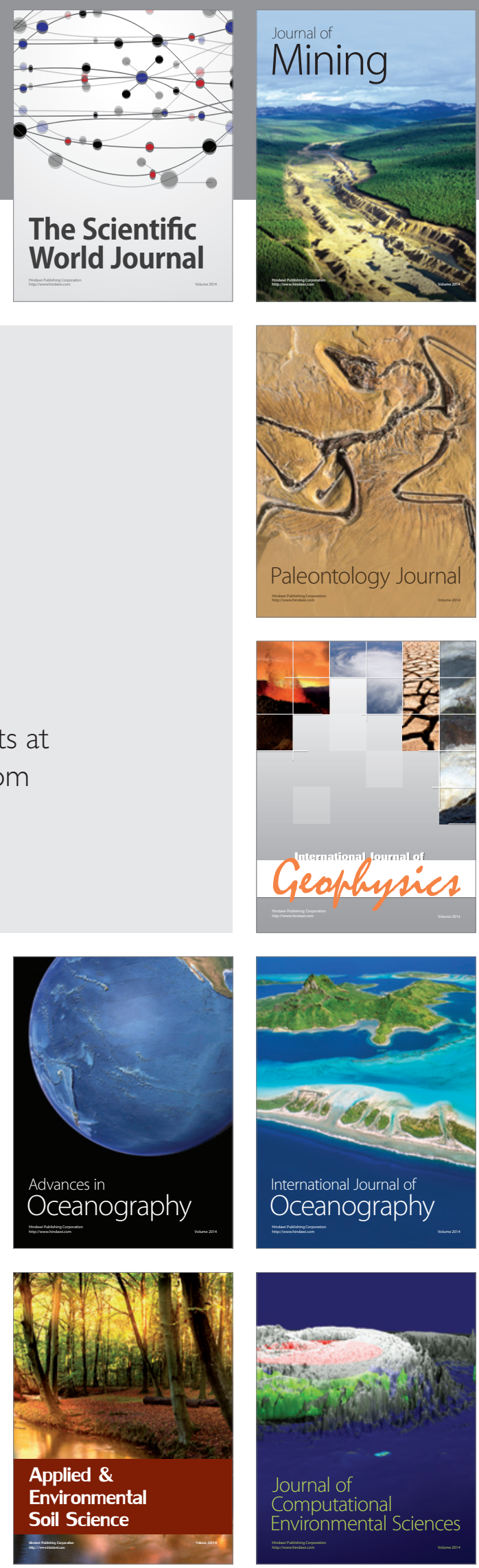